\title{
Orientation Selectivity from Very Sparse LGN Inputs in a Comprehensive Model of Macaque V1 Cortex
}

\author{
- Logan Chariker, ${ }^{1}$ Robert Shapley, ${ }^{2}$ and Lai-Sang Young ${ }^{1,2}$ \\ ${ }^{1}$ Courant Institute of Mathematical Sciences, and ${ }^{2}$ Center for Neural Science, New York University, New York, New York 10003
}

\begin{abstract}
A new computational model of the primary visual cortex (V1) of the macaque monkey was constructed to reconcile the visual functions of V1 with anatomical data on its LGN input, the extreme sparseness of which presented serious challenges to theoretically sound explanations of cortical function. We demonstrate that, even with such sparse input, it is possible to produce robust orientation selectivity, as well as continuity in the orientation map. We went beyond that to find plausible dynamic regimes of our new model that emulate simultaneously experimental data for a wide range of V1 phenomena, beginning with orientation selectivity but also including diversity in neuronal responses, bimodal distributions of the modulation ratio (the simple/complex classification), and dynamic signatures, such as gamma-band oscillations. Intracortical interactions play a major role in all aspects of the visual functions of the model.
\end{abstract}

Key words: computational model; diversity; LGN input; macaque V1; orientation selectivity; population dynamics

\section{Significance Statement}

We present the first realistic model that has captured the sparseness of magnocellular LGN inputs to the macaque primary visual cortex and successfully derived orientation selectivity from them. Three implications are (1) even in input layers to the visual cortex, the system is less feedforward and more dominated by intracortical signals than previously thought, (2) interactions among cortical neurons in local populations produce dynamics not explained by single neurons, and (3) such dynamics are important for function. Our model also shows that a comprehensive picture is necessary to explain function, because different visual properties are related. This study points to the need for paradigm shifts in neuroscience modeling: greater emphasis on population dynamics and, where possible, a move toward data-driven, comprehensive models.

\section{Introduction}

Orientation selectivity (OS) is one of the most salient characteristics of the primary visual cortex (V1) of the macaque monkey. Hubel and Wiesel (1962) proposed a theory for OS framed in terms of feedforward convergence of LGN cells with receptive fields (RFs) aligned in visual space. We were compelled to revisit their ideas in the light of experimental findings about the extreme sparseness of LGN input to V1.

We focus on V1 layer 4C $\alpha$ because orientation selectivity and spatial frequency (SF) selectivity are already observable in this cortical input layer (Livingstone and Hubel, 1984; Ringach et al.,

\footnotetext{
Received Aug. 16, 2016; revised Sept. 21, 2016; accepted 0ct. 7, 2016.

Author contributions: R.S. and L.-S.Y. designed research; L.C., R.S., and L.-S.Y. performed research; L.C. contributed unpublished computer codes; L.C., R.S., and L.-S.Y. analyzed data; R.S. and L.-S.Y. wrote the paper.

This work was supported in part by National Science Foundation Grant DMS-1363161 to L.-S.Y and also by a grant from the Swartz Foundation. This research was performed on the High Performance Computing resources at New York University. We thank Kevin Lin for preliminary studies; and Luiz Carlos Silveira, Michael Hawken, Dario Ringach, I-Chun Lin, Alessandra Angelucci, and Luke Hallum for helpful discussions.

The authors declare no competing financial interests.

Correspondence should be addressed to Lai-Sang Young, Courant Institute of Mathematical Sciences, 251 Mercer Street, New York University, New York NY 10012. E-mail: Isy@cims.nyu.edu.

DOI:10.1523/JNEUROSCI.2603-16.2016

Copyright $\odot 2016$ the authors $\quad 0270-6474 / 16 / 3612368-17 \$ 15.00 / 0$
}

2002; Zhu et al., 2010). Layer $4 \mathrm{C} \alpha$ receives input from the magnocellular LGN layers (Chatterjee and Callaway, 2003). According to anatomical evidence (see Results), the magnocellular LGN input to V1 is very sparse (Connolly and Van Essen, 1984; Silveira and Perry, 1991; Angelucci and Sainsbury, 2006). Layer 4C $\alpha$ in each V1 hypercolumn (Lund et al., 2003) receives only $\sim 10$ direct magnocellular inputs, and a total of 30 LGN inputs altogether counting up direct and ramifying axons from neighboring hypercolumns. These 30 LGN inputs are driving 3000 excitatory (E) and 1000 inhibitory (I) cortical neurons.

The anatomical data cited above lead to the following geometric/combinatorial questions. In a patch of 10-20 LGN cells, one-half ON, one-half OFF, is it possible to fit two or three approximately parallel receptive field subregions, as in the HubelWiesel picture, each driven by ON (or OFF) LGN cells, with distances between the subregions that would support the correct spatial frequency preference of the V1 neuron? And, would model cortical neurons acquire the ability to discern many orientations around the clock, as observed in real V1 (Obermayer and Blasdel, 1993), from the same set of sparse inputs?

The new computational model of layer $4 \mathrm{C} \alpha$ that we have constructed answers both of these questions in the affirmative. Ori- 
A

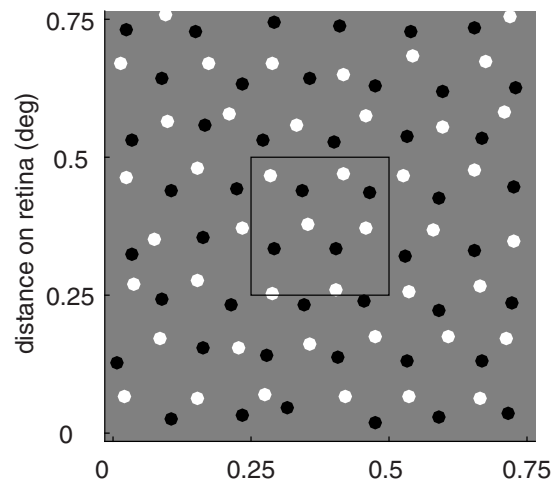

$\mathrm{R}$
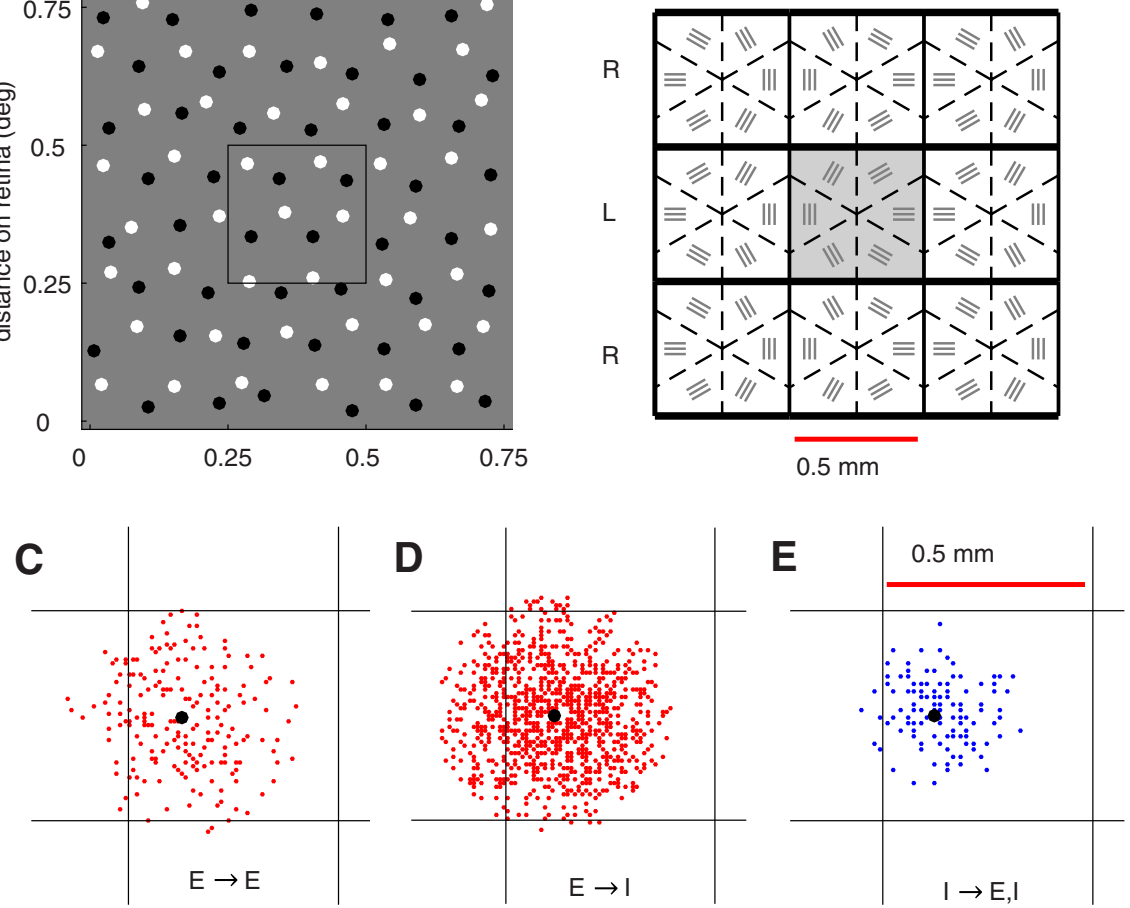

Figure 1. LGN input and corticocortical coupling of $E$ and I cells. A, Receptive field centers of $M$ retinal ganglion cells or magnocellular LGN cells in the locations of their projections to V1 cortex. ON cells are indicated by white, and OFF cells by black, against a gray background. The ganglion cell density is from the study by Silveira and Perry (1991). The square drawn in the center corresponds to the retinal region that projects to a single hypercolumn (HC). $B$, The nine $\mathrm{HCs}$ of the model with the intended orientation map drawn in. $\mathbf{C}-\boldsymbol{E}$, Connectivity examples: presynaptic $\mathrm{E}$ input (red) to an $\mathrm{E}$ cell (black dot; $\boldsymbol{C}$; presynaptic $\mathrm{E}$ inputs (red) to an I cell (D); and presynaptic I inputs (blue) to an $\mathrm{E}$ (or I) cell (E). The square in each plot represents an HC.

\section{Materials and Methods}

We will discuss in separate sections the general layout, or architecture, of our network model, the equations of neuronal dynamics, and parameter determination. For readers who wish to bypass model details, we recommend proceeding directly to Results.

\section{Model layout}

The main component of our model is that of a small piece of layer $4 \mathrm{C} \alpha$ of the macaque $\mathrm{V} 1$ cortex located at $\sim 5^{\circ}$ eccentricity. Also modeled are the two sheets of LGN cells that project to this region of $4 \mathrm{C} \alpha$, as well as outputs of layer 6 , the feedback layer to $4 \mathrm{C} \alpha$.

Magnocellular LGN layers. The input to layer $4 \mathrm{C} \alpha$ in our model consists of regions of the magnocellular layers of the LGN. Data from the studies by Connolly and Van Essen (1984) and Silveira and Perry (1991) indicate that there are on average $\sim 10 \mathrm{LGN}$ cells ( $5 \mathrm{ON}$ and $5 \mathrm{OFF}$ ) that project to each hypercolumn (HC); see Results, Input patterns of LGN to V1. In the model, we started modeling the LGN with a (regular) triangular lattice on the plane, which we identified with visual space. Assuming that the centers of the receptive fields of $\mathrm{ON}$ LGN cells correspond to points in this lattice, we placed the OFF cells at the barycenters of the triangles defined by the ON lattice. Lattice spacing was chosen so that neighboring $\mathrm{ON}$ (or, respectively, OFF) cells are $\sim 0.125^{\circ}$ apart, resulting in 10 cells/HC. We then perturbed randomly and independently each lattice point to match the retinal mosaics of $\mathrm{M}$ retinal ganglion cells.

Figure $1 A$ shows the distribution of receptive field centers of ON and OFF LGN cells in

entation selectivity is passed to cortex, with a great deal of help from recurrent cortical interactions. As shown in Results, our model exhibits the full range of orientation and spatial frequency selectivity found in V1. It takes weakly tuned inputs from sparse LGN afferents, and, via recurrent inhibitory and excitatory synaptic interaction, sharpens them and smoothes out the discrete set of orientations from LGN into a continuous map.

Our model goes far beyond accounting for OS and orientation maps. It shows that many V1 functions are linked. These include, in addition to OS, the bimodal distribution of modulation ratio (MR) that is an index of the simple/complex classification (see Fig. 4; Skottun et al., 1991), the wide diversity in selectivity and neuronal response magnitudes (see Figs. 6, 8; Ringach et al., 2002), as well as the emergence of gamma rhythms when driven by optimal gratings (see Fig. 9; Volgushev et al., 2002; Kayser and König, 2004).

Our analysis shows that dynamic interactions among cortical neurons are the single most important factor that binds together these different functions of V1. Recurrent excitation, indirect suppression, and the competition and balancing between the excitatory and inhibitory populations shape neuronal responses to stimuli. These interactions give rise to many emergent phenomena, i.e., phenomena that cannot be predicted from the behaviors of single neurons alone.

We propose that the model presented here can serve as a starting point in the creation of a larger dynamic picture, one that connects anatomical structures, dynamics, and cortical functions, and extends to the rest of cerebral cortex. the lattice, together with the scale of one $\mathrm{HC}$ in visual space. Determining plausible input patterns of LGN cells to cortex based on anatomical and physiological data is a major part of the present modeling effort. Our choices of LGN input patterns are reported in Results.

Layer $4 C \alpha$. We modeled nine HCs of $4 \mathrm{C} \alpha$ arranged in three ocular dominance columns (Fig. 1B). Each HC measures $0.5 \times 0.5 \mathrm{~mm}^{2}$ and is divided into regions where cells are intended to have similar orientation preferences, following the pinwheel pattern of orientation selectivity seen in experiments (Obermayer and Blasdel, 1993). Following Beaulieu et al. (1992), we used cell densities of $\sim 4000$ neurons/HC, three-quarters of which are E cells and the rest are I cells. The I neurons are assumed to be a homogeneous population of local-circuit basket cells, a reasonable approximation for layer 4C $\alpha$ (Defelipe et al., 1999). E and I neurons are uniformly distributed in the model cortex.

The probability of connection among model cells is dependent on distance and cell types (E or I), while the strength of connection is independent of distance. This approach is based on intracellular data (Oswald and Reyes, 2008) and is more realistic than all-to-all coupling with synaptic strength decreasing with distance, as was done in some previous large-scale models of V1 (McLaughlin et al., 2000; Tao et al., 2004, 2006). As discussed in Results (see Fig. 6), the observed diversity in OS and other cortical properties depended on the probabilistic connectivity used here. For presynaptic E neurons, connection probabilities are given by Gaussians with $\mathrm{SD}=200 / \sqrt{ } 2 \mu \mathrm{m}$; and for presynaptic I cells, SD $=125 / \sqrt{ } 2$ $\mu \mathrm{m}$ (Fitzpatrick et al., 1985; Yoshioka et al., 1994). Peak connection probability among E cells is $\sim 15 \%$ on average (i.e., we scaled the Gaussian describing the spatial dependence of connection probability to have a peak of 0.15). According to Holmgren et al. (2003) and Oswald and Reyes (2008), I cell connections are much denser (from 50\% to 100\%); we set the peak connection probabilities for $\mathrm{E} \rightarrow \mathrm{I}, \mathrm{I} \rightarrow \mathrm{E}$, and $\mathrm{I} \rightarrow \mathrm{I}$ to be $60 \%$ 
(Fig. 1C,D,E). The consequences of all these choices can be seen in Figure $1 C-E$, which shows examples of the spatial extent of E-E, E-I, I-E, and I-I couplings in the model. As can be observed in Figure 1, the spatial reach of E neurons is larger than that of I neurons, while the E-E coupling is the sparsest.

The numbers of connections and cell densities imply that, on average, an E cell has $\sim 200 \mathrm{E}$ cells and $\sim 100$ I cells presynaptic to it, while an I cell has, on average, $\sim 750 \mathrm{E}$ cells and $\sim 100$ I cells presynaptic to it (Fig. $1 C-E)$. These are mean values; the actual numbers of presynaptic inputs fluctuate from cell to cell. Connectivity between each specific pair of neurons was determined first by a coin flip (with a suitable probability of "yes"). Outliers in the distributions of presynaptic neurons were then discarded to prevent, for example, domination by cells with too many presynaptic E neurons (Fig. 1C-E).

Observe that the numbers of presynaptic neurons computed from cell densities and connection probabilities are in the hundreds, not tens of thousands (as in the continuum limit of van Vreeswijk and Sompolinsky, 1996); each presynaptic cortical cell makes multiple synaptic connections on its target neuron (Martin, 1988).

Outputs from layer 6 . Layer $4 \mathrm{C} \alpha$ receives substantial feedback primarily from layer 6 (L6) (Callaway, 1998), the effects of which are incorporated in the model. L6 receives input from multiple layers of V1 as well as LGN (Callaway, 1998; Sincich and Horton, 2005), and its neuronal population is known to be very diverse (Wiser and Callaway, 1996); constructing a detailed model of its dynamics would present formidable challenges. For our purposes, however, it is sufficient to model only the outputs of the subpopulation of L6 that project to $4 \mathrm{C} \alpha$. We modeled these outputs as a collection of spike trains, one for each L6 neuron.

From the cell density of L6 (Beaulieu et al., 1992) and the small fraction of E cells that project to layer 4C $\alpha$ (Wiser and Callaway, 1996), we estimated that $\sim 300 \mathrm{~L} 6$ neurons/HC have ascending axons that terminate in 4C $\alpha$. The axonal spreads are large (Wiser and Callaway, 1996); in the model, we assumed that most (approximately five-sixths) of the synaptic contacts of a layer 6 cell occur in a disk of radius $\sim 180 \mu \mathrm{m}$, while the rest can extend as far as $\sim 360 \mu \mathrm{m}$. In the absence of experimental guidance on connection probabilities between L6 and 4C $\alpha$ neurons, we assumed that they are similar to those within $4 \mathrm{C} \alpha$; this gives, for example, an average of $\sim 50$ presynaptic L6 neurons, represented by a corresponding number of spike trains, for each $\mathrm{E}$ cell in $4 \mathrm{C} \alpha$.

Spontaneous spiking of L6 neurons was modeled as Poissonian, at 0.5-10 spikes/s (Ringach et al., 2002). L6 spike trains were tuned for orientation (Ringach et al., 2002). Specifically, if $f_{6, \max }$ represents the mean firing rate of an L6 neuron when driven by its optimally oriented grating pattern at full contrast, we scaled this number down to approximately $0.25^{\star} f_{6, \max }$ for the response to an orthogonal grating. Also incorporated in the model are the facts that (1) a majority of L6 neurons are complex (Ringach et al., 2002), and (2) there is partial synchronization in the gamma band of frequencies for nearby L6 neurons (Xing et al., 2012).

\section{Equations of neuronal dynamics}

Dynamics of LGN cells. Following the study by Lin et al. (2012), we modeled the dynamics of individual LGN cells by the integrate-and-fire equation, as follows:

$$
V^{\prime}(t)=-c V(t)+I^{+/-}(t)+S_{\text {noise }} \sum_{i=1, \infty} s_{i} \delta\left(t-t_{i}\right),
$$

where $V$ is membrane potential; $c=100$ is the leak rate ( $t$ is in seconds); $I^{+}$and $I^{-}$are deterministic currents entering ON and OFF LGN cells, respectively; $S_{\text {noise }}$ is the coupling coefficient of a Poisson-timed noise term; $s_{i}$ is \pm with equal probability; and $t_{i}$ are the arrival times of the Poissonian noise inputs. When $V$ reaches a threshold $V_{\text {thresh }} \sim 1$, the potential is reset to 0 , and a spike is sent to all postsynaptic cells in $4 \mathrm{C} \alpha$. For a sinusoidal grating drifting in the direction $u$ (unit vector) with temporal frequency $w$, the current $I(t, x)$ into an LGN cell, the center of whose RF corresponds to location $x$ in visual space is given by the following: where $I_{0}=100$ (as in the study by Lin et al., 2012), $\varepsilon$ is contrast, $C(|\mathrm{u}|)$ is a function encoding the dependence of firing rate on the spatial frequency of the grating (modeled as a standard difference-of-Gaussians, as in the study by Zhu et al., 2010), and $p(t, x)=w t+\langle x$,wu $\rangle$ gives the phase at location $x$ (where $\langle x, w u\rangle$ is the inner product). Constants are chosen so that the background (bg) firing rate of an LGN cell is $\sim 20$ spikes/s, and, when driven by a grating at full contrast, the peak firing rate is $\sim 100$ spikes/s (Hawken et al., 1996). When driven, this LGN model produces firing patterns significantly closer to those of real LGN cells (Reich et al., 1997; Lin et al., 2012) than Poisson models. The more realistic LGN model excited V1 cells more effectively than Poisson drive (Lin et al., 2012).

Dynamics of cortical cells in layer $4 C \alpha$. Consider a model neuron, $n$, of type $\sigma=\mathrm{E}$ or I. To model the time evolution of its membrane potential, we used normalized voltage units where resting potential $V_{\text {rest }}=0$, and spike threshold $V_{\text {th }}=1$. The membrane potential of the $n$th neuron $v^{n}$ is driven toward the normalized spike firing threshold $V_{\text {th }}=1$ by the following leaky integrate-and-fire (LIF) equation:

$$
d v^{n} / d t=-g_{R, \sigma} v^{n}-g_{E}^{n}(t)\left(v^{n}-V_{\mathrm{E}}\right)-g_{I}^{n}(t)\left(v^{n}-V_{I}\right),
$$

where $v^{n}$ is in normalized units, time $t$ is in seconds, the leakage conductance $g_{R, \sigma}$ is set to $50 / \mathrm{s}$ for $\sigma=E$ and $1.33 * 50 / \mathrm{s}$ for $\sigma=I$ (Beierlein et al., 2003). Here $g_{E}^{n}(t)$ and $g_{I}^{n}(t)$ are the $\mathrm{E}$ and I conductances of neuron $n$ at time $t$; their time evolutions are described below. Finally $V_{\mathrm{E}}$ and $V_{\mathrm{I}}$ are the $E$ and I reversal potentials, which in normalized coordinates are $14 / 3$ and $-2 / 3$ respectively. When $v^{n}$ reaches $V_{\text {th }}$, a spike is fired, and $v^{n}$ is reset to 0 , where it is held for a refractory period $=2 \mathrm{~ms}$. The biophysical constants above are textbook (Koch, 1999).

The evolution of $g_{I}^{n}(t)$, the I conductance of neuron $n$, is given by the following:

$$
g_{I}^{n}(t)=S^{\sigma I} \sum_{i \in P_{4 C, I}(n)} \sum_{k=1, \infty} G_{\mathrm{GABA}}\left(t-t_{k}^{i}\right)
$$

where $S^{\sigma I}$ is the synaptic weight, or the constant describing the change in I conductance in neuron $n$ upon receiving synaptic input from an inhibitory neuron. Synaptic weights vary by $\sim 10 \%$ from neuron to neuron; for simplicity, we write only their mean, which we assume depends only on the type $\sigma$ of neuron $n$, hence the notation $S^{\sigma I}$. The first summation in the equation for $g_{I}^{n}(t)$ is over $P_{4 C, I}(n)$, defined to be the set of all I neurons in layer $4 \mathrm{C} \alpha$ that synapse on neuron $n$. The second summation is over the spikes fired by neuron $i$. Specifically, $t_{k}^{i}$ is the time of the $k$ th spike in neuron $i . G_{\mathrm{GABA}}(s)$ describes the time course of I conductance for a neuron when a spike is fired by a presynaptic I neuron at time $s=0$.

The E conductance $g_{E}^{n}(t)$ is the sum of four synaptic conductances: (I), coming from LGN; (II), from layer 4C $\alpha$; (III), layer 6; and (IV), neuromodulatory influences from the rest of the brain or body. We discuss each of these terms separately. First:

$$
(\mathrm{I}):=S^{\sigma, \mathrm{LGN}} \sum_{i \in P_{\mathrm{LGN}}(n)} \sum_{k=1, \infty} G_{\mathrm{AMPA}}\left(t-t_{k}^{i}\right)
$$

As above, $S^{\sigma, \mathrm{LGN}}$ is the synaptic weight from an LGN spike for a postsynaptic cell of type $\sigma, P_{\mathrm{LGN}}(n)$ is the set of LGN cells presynaptic to neuron $n$, and $G_{\mathrm{AMPA}}(s)$ is the conductance time course for AMPA. Likewise:

$$
\text { (II) }:=S^{\sigma, \mathrm{E}} \sum_{i \in P_{4 C, \mathrm{E}}(n)} \sum_{k=1, \infty}\left\{\rho_{A}^{\sigma} G_{\mathrm{AMPA}}\left(t-t_{k}^{i}\right)\right.
$$

$$
\left.+\rho_{N}^{\sigma} G_{\mathrm{NMDA}}\left(t-t_{k}^{i}\right)\right\} .
$$

The meanings of the terms are analogous to that given before: $P_{4 C, E}(n)$ denotes the set of $\mathrm{E}$ neurons in layer $4 \mathrm{C} \alpha$ that synapse on neuron $n$, and $\rho_{A}^{\sigma}$ and $\rho_{N}^{\sigma}$ denote the fractions of synaptic input received by AMPA and NMDA receptors in a postsynaptic neuron of type $\sigma$. The feedback term (III) is identical to (II), except that $P_{4 C, E}(n)$ is replaced by $P_{6, E}(n)$, the set of E neurons in layer 6 that synapse on neuron $n$, and $S^{\sigma E}$ is replaced by $S_{6}^{\sigma E}$, a different number. Finally, the term (IV), in which we have lumped the influence of multiple modulatory substances, to be thought of as mostly but not limited to acetylcholine, is modeled approximately (in the absence of more precise information) as follows:

$$
(\mathrm{IV}):=S^{\mathrm{amb}} \sum_{\mathrm{Poisson}, r_{\sigma}} G_{\mathrm{AMPA}}\left(t-t_{k}\right) .
$$

$$
I^{+/-}(t, x)=I_{0}(1+\varepsilon C(|u|) \sin (p(t, x)))
$$



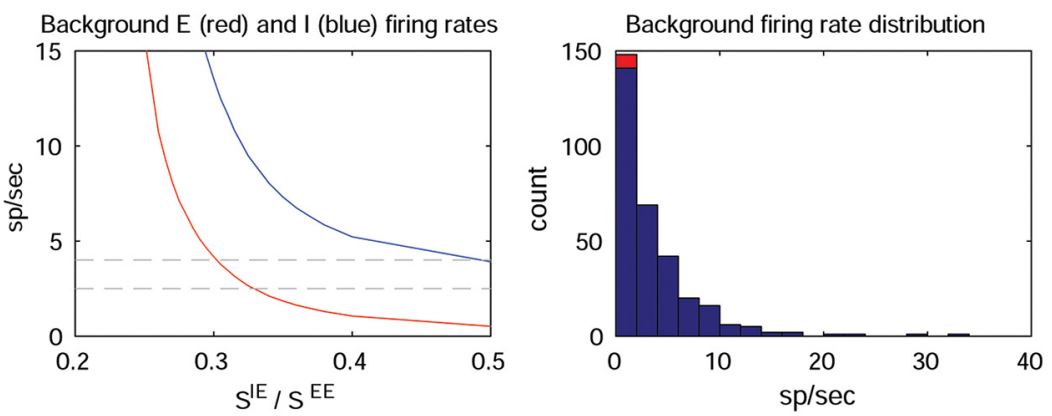

Figure 2. Determination of $S^{I E} / S^{E E}$. A, Dependence of background firing rates on $S^{I E} / S^{E E}$. The target mean background firing rate for $E$ cells is 2.5- 4 spikes/s (dashed lines), so the $S^{I E} / S^{E E}$ ratio needs to be $0.3-0.32$. Note that in this window, I firing rates are three to four times the $E$ firing rates. $B$, Distribution of the by firing rates of the population of $E$ neurons with $S^{I E} / S^{E E}=0.3$.

Here "amb" is shorthand for "ambient." The summation is over Poisson pulses, of size $S^{\text {amb }}$ and at rate $r_{\sigma}$, occurring at times $t_{k}$. The times of occurrence of ambient pulses are independent from neuron to neuron.

The functions $G_{\mathrm{GABA}}, G_{\mathrm{AMPA}}$, and $G_{\mathrm{NMDA}}$ are similar to those used by Tao et al. (2004), with rise times of a few milliseconds; and decay times of $\sim 5 \mathrm{~ms}$ for $G_{\mathrm{GABA}}, \sim 3 \mathrm{~ms}$ for $G_{\mathrm{AMPA}}$, and $\sim 80 \mathrm{~ms}$ for $G_{\mathrm{NMDA}}$. Following the study by Stratford et al. (1996), we further assumed that each E-to-E spike carries a synaptic failure rate of up to $20 \%$.

We remark that even after all the parameters have been fixed, one cannot solve for the quantities $t_{k}^{i}$ (= the arrival times of spikes) in the equations above explicitly. A neuron spikes when its membrane potential reaches a certain threshold that is largely determined by the net effect of the spiking activities of its presynaptic $\mathrm{E}$ and I neurons, which themselves are influenced by neurons presynaptic to them. In particular, firing rates cannot be expressed in terms of the parameters above. We choose parameters aiming to hit a target distribution of firing rates; that is the best we can do. As simple as the form of the LIF equations may appear, the interactions among neurons are complicated, and it is these interactions that shape collective behavior.

\section{Parameter determination}

Parameters were set systematically based as much as possible on experimental data. First, we fixed those constants for which there is some biological guidance, such as the ratios of AMPA to NMDA in E synapses. We set $\rho_{A}^{E}=0.8, \rho_{N}^{E}=0.2, \rho_{A}^{I}=0.67$, and $\rho_{N}^{I}=0.33$, as NMDA is known to be more prevalent in I neurons (Lisman et al., 2008). We set $S^{\mathrm{I}, \mathrm{LGN}}=$ $2.1^{\star} S^{\mathrm{EE}}, S^{\mathrm{I}, \mathrm{LGN}}=3^{*} S^{\mathrm{EE}}, S_{6}^{E E}=0.5^{*} S^{\mathrm{EE}}$ (Stratford et al., 1996; Beierlein et al., 2003), and assumed a synaptic failure rate up to $50 \%$ for L6 neurons (Stratford et al., 1996). As the mean firing rate of the particular subpopulation of L6 that project to $4 \mathrm{C} \alpha$ is not known, we set $f_{6 \text {, max }}$ at $\sim 40$ spikes/s, well within the range of the entire L6 population.

The choice of $S^{\mathrm{amb}}=0.01$ was arbitrary, the only known constraint being that $S^{\mathrm{amb}}$ should be small (acetylcholine is known to be delivered in very small pulses; Disney et al., 2012). There was less guidance for the ambient neuromodulatory rates $r_{E}^{A}$ and $r_{I}^{A}$, except that the neuromodulation alone should not cause spiking in layer $4 \mathrm{C} \alpha$ (Soma et al., 2012). We used $r_{E}^{A}, r_{I}^{A} \sim 250 / \mathrm{s}$. The choices of the neuromodulatory rates have little effect on orientation selectivity

Determining $S^{\mathrm{EE}}, \mathrm{S}^{\mathrm{EI}}, \mathrm{S}^{\mathrm{IE}}$, and $\mathrm{S}^{\mathrm{II}}$. We set $S^{E E}=0.028$, a justification being that starting from a reasonable membrane potential and conductance, it takes 10-20 excitatory pulses in quick succession to drive a cell across threshold if we use an $S^{E E}$ value between 0.02 and 0.03 (Stratford et al., 1996).

Once $S^{E E}$ was fixed, we used the following experimental guidance to set $S^{E I}$. We may express the ratio of I conductance to E conductance as follows:

$$
g_{I}^{E} / g_{E}^{E}=W^{\star} X^{\star} Y * Z,
$$

where $W=$ (firing rate of I neurons in $4 \mathrm{C} \alpha$ )/(firing rate of $\mathrm{E}$ neurons in $4 \mathrm{C} \alpha) ; X=$ (no. of presynaptic I neurons in $4 \mathrm{C} \alpha$ )/(no. of presynaptic $\mathrm{E}$ neurons in $4 \mathrm{C} \alpha$ ); $Y=$ correction of $W^{\star} X$ to include sources of $\mathrm{E}$ currents from outside of $4 \mathrm{C} \alpha$; and $Z=S^{E I} / S^{E E}$.
Substituting $g_{I}^{E} / g_{E}^{E} \sim 3$ based on experimental data (Borg-Graham et al., 1998), $W \sim 4$ (Swadlow, 1988), $X \sim 1 / 2$ (see Materials and Methods, Model Layout, above), and $Y \sim 2 / 3$ (a guess based on the results of the study by Binzegger et al., 2009), we obtain $Z \sim 2.25$. In the model, we used $S^{E I}=2 * S^{E E}$.

Then we fixed the relation between $S^{I I}$ and $S^{E I}$, for example, by setting $S^{I I}$ to be uniformly distributed between $0.65{ }^{*} S^{E I}$ and $0.85{ }^{\star} S^{E I}$. Our rationale for taking $S^{I I}$ to be smaller than $S^{E I}$ is that, in addition to the usual chemical synapses, some pairs of I neurons are known to be electrically coupled (Gibson et al., 2005), and electrical coupling means that the I neurons excite rather than suppress one another.

Of the four synaptic weight constants $S^{X Y}$, the most sensitive is $S^{I E}$; more than the other $S^{X Y}$ weight constants, a small change in $S^{I E}$ can have a large effect on the behavior of the system. This is in part due to the large numbers of presynaptic E neurons to I cells (Fig. 1D). For this reason, we located a suitable value of $S^{I E}$ through parameter exploration. With all $S^{X Y}$ weight constants fixed, except for $S^{I E}$, we determined $S^{I E}$ guided by the bg firing rates for E neurons. More precisely, we found that, without exception, the mean bg E firing rate decreases monotonically as $S^{I E} / S^{E E}$ is increased (Fig. 2). This dependence is expected, and it allows one to choose the value of $S^{I E} / S^{E E}$ that gives the mean bg firing rates of $E$ neurons that one requires to emulate experimental mean bg firing rate data at 3-4 spikes/s.

We do not claim to have performed an exhaustive search for all parameters (which is not feasible given the dimensionality of parameter space), but have found, through numerical exploration, that there is considerable flexibility in the sense of producing viable model outputs provided that excitation and inhibition in the model are well balanced. Below, we give three examples of how this E/I balancing is accomplished in the procedure above, as well as the properties that are affected. None of the parameter variations below has significant effects on OS, diversity, and dynamic linkage to function, as discussed in Results.

Example 1: varying $\mathrm{S}^{\mathrm{EI}}$. We have explored varying $S^{E I}=c^{\star} S^{E E}$ for $c$ in the range $(1.6,2.8)$. Using the parameter determination procedure (Fig. 2) for $S^{I E} / S^{E E}$, we find a larger $S^{I E}$ value for smaller $c$ values and a smaller $S^{I E}$ value for larger $c$ values, so that the total inhibitory capability of the system remains approximately constant. What changes is the I cell firing rate: a larger $c$ value leads to lowered I cell firing, as can be expected since each I cell spike is more powerful.

Example 2: increasing $\mathrm{S}^{\text {II }}$. If $S^{I I}$ increases, our procedure for determining $S^{I E}$ (Fig. 2) gives a larger $S^{I E}$ value to compensate for the extra inhibition to I neurons. A side effect of increased $S^{I I}$ is that I cell voltages sit lower on average (i.e., the membrane is more hyperpolarized), and I cell spiking becomes a little less synchronized when driven.

Example 3: varying the amount of ambient drive. Varying ambient input spike rates $r_{E}^{A}$ and $r_{I}^{A}$ by similar amounts has little effect, except that too low an ambient drive causes the system to become more synchronized than is realistic in background. Favoring ambient $\mathrm{E}$ or I over the other is balanced by the procedure for selecting $S^{I E}$, as indicated before.

Trimming variation and introducing "egalitarian" redistributions. E neurons that receive significantly more excitatory input may fire more, silencing other E neurons via recurrent inhibition. Such competition is part of the dynamic picture, but in too extreme a form, it makes the model unrealistic. For this reason, we had to trim down the variability in the number of presynaptic E neurons for E cells, as explained in Materials and Methods, Model Layout. It turns out that we will also have to introduce variability for a different reason: to compensate neurons that do not receive adequate feedforward input. This is discussed in Results, Input patterns of LGN to V1.

Monocular versus binocular simulations. In model simulations, both eyes were assumed to be open when the visual stimuli were presented. Because much of the experimental data used for validation was obtained with one eye occluded, we also simulated monocular stimulus presenta- 
tion, and the results (data not shown) are very similar to the binocular case.

Summary of parameter values used in the simulations in

this article

Leakage conductance, excitatory neurons, $g_{R}^{E}=50 / \mathrm{s}$; leakage conductance, inhibitory neurons, $g_{R}^{I}=66 / \mathrm{s}$; coupling weight LGN $\rightarrow$ E cells, $S^{E, \mathrm{LGN}}=0.059$; coupling weight LGN $\rightarrow$ I cells, $S^{I, \mathrm{LGN}}=0.084$; coupling weight cortical E $\rightarrow \mathrm{E}, S^{E E}=0.028$; coupling weight cortical $\mathrm{E} \rightarrow \mathrm{I}, S^{I E}=$ 0.0095 ; coupling weight cortical $\mathrm{I} \rightarrow \mathrm{E}, S^{E I}=0.056$; coupling weight cortical I $\rightarrow$ I, $S^{I I}=$ uniformly distributed in $(0.036,0.048)$; coupling weight layer $6 \rightarrow \mathrm{E}, S_{6}^{E E}=0.014$; coupling weight layer $6 \rightarrow \mathrm{I}, S_{6}^{I E}=$ 0.0047 ; coupling weight ambient, $S^{\mathrm{amb}}=0.01$; ambient firing rate, $r_{E}^{A}=$ $r_{I}^{A}=250 / \mathrm{s} ;$ AMPA fraction of E conductance, $\rho_{A}^{E}=0.8$; NMDA fraction of E conductance, $\rho_{N}^{E}=0.2$; AMPA fraction of I conductance, $\rho_{A}^{I}=0.67$; NMDA fraction of I conductance, $\rho_{N}^{I}=0.33$; and peak-driven firing rate in layer $6, f_{6, \max } \sim 40 / \mathrm{s}$.

\section{Results}

Input patterns of LGN to V1

Calculation of sparse LGN magnocellular input to V1 cortex

layer $4 C \alpha$

An important new feature of our model is that it takes into account the very sparse LGN input to macaque V1. That the LGN input is extremely sparse can be gleaned from known anatomical data. According to Silveira and Perry (1991), the M retinal ganglion cell density at $5^{\circ}$ eccentricity is $3500 / \mathrm{mm}^{2}$. If we take the conversion factor of $[200 \mu \mathrm{m}$ (on the retina)]/[degree of visual angle] for the Java monkey Macaca fascicularis (Silveira and Perry, 1991), then $\mathrm{M}$ cell density $=140 \mathrm{M}$ ganglion cells $/ \mathrm{deg}^{2}$ at $5^{\circ}$ eccentricity. The cortical magnification factor in $M$. fascicularis $\mathrm{V} 1$ at $5^{\circ}$ eccentricity is $\sim 2 \mathrm{~mm} / \mathrm{deg}$ (Xing et al., 2009). Therefore, one hypercolumn in V1 cortex $(0.5 \times 0.5 \mathrm{~mm})$ at $5^{\circ}$ eccentricity corresponds to approximately $\left(0.25^{\circ}\right)^{2}=1 / 16 \mathrm{deg}^{2}$. Then the number of $\mathrm{M}$ ganglion cells that provide direct input to one hypercolumn would be $1 / 16^{*} 140$, or approximately nine cells. We round that number off to 10 . A similar calculation can be performed with the macaque LGN data from the study by Connolly and Van Essen (1984). They provide an estimate of the magnocellular LGN density at $5^{\circ}$ of $\sim 160 / \mathrm{deg}^{2}$, which is in close agreement with the $\mathrm{M}$ retinal ganglion cell density estimate by Silveira and Perry (1991) of 140/ $\mathrm{deg}^{2}$. This yields the estimate of 10 magnocellular LGN cells providing direct LGN input to each hypercolumn. The data from the study by Connelly and Van Essen (1984) indicate that a similar estimate would apply also at $10^{\circ}$ eccentricity. The concordance of data between the studies by Silveira and Perry (1991) and Connelly and Van Essen (1984) suggests that within the central $10^{\circ}$ of the visual field the same number of $\mathrm{M}$ retinal ganglion cells and magnocellular cells represent the same region of visual space.

With approximately $10 \mathrm{M}$ retinal ganglion cells and a corresponding number of magnocellular LGN cells providing direct input to each $\mathrm{HC}$, branching of magnocellular axons from neighboring HCs (Blasdel and Lund, 1983; Lund et al., 1993; Angelucci and Sainsbury, 2006) provides another 20 or so LGN inputs to each $\mathrm{HC}$, making a total of no more than 30 thalamic inputs that drive the 4000 neurons in the HC of the model. Furthermore, Angelucci and Sainsbury (2006) reported that in layer $4 \mathrm{C} \alpha$, a region $300 \mu \mathrm{m}$ in diameter is contacted by no more than $11 \mathrm{LGN}$ cells, and they proposed that the numbers of LGN inputs to cortical cells are likely much smaller. Their estimate is consistent with the numbers above, as well as the RF profiles obtained by Yeh et al. (2009) (and C. I. Yeh, D. Xing, P. E. Williams, and R. M. Shapley, unpublished observations).
Given the sparseness of LGN input to V1, it is a challenge for any model to generate the full repertoire of the visual functions of V1. Our model met this challenge with a specific set of LGN input patterns, which were designed to be as consistent as possible with anatomical and physiological data. This is discussed in the Numbers and templates section below. We also found that the distribution of the MR and SF preferences of V1 neurons are strong constraints on the choice of LGN input patterns. This is discussed in the Modulation ratios and nLGN section below.

\section{Numbers and templates}

Following the optical imaging data from the study by Obermayer and Blasdel (1993), we sought to assign to each neuron in a designated orientation domain in layer $4 \mathrm{C} \alpha$ (Fig. $1 B$ ) a configuration of LGN cells that has the potential to produce two or three ON/OFF subregions aligned in the direction specified. This task has the following constraints: (1) each ON (or OFF) subregion cannot be represented by more than one row of LGN cells, or the number of LGN inputs would be too large, contradicting the findings of the study by Angelucci and Sainsbury (2006); (2) for the same reason, each row cannot exceed two to three LGN cells; (3) because the peak response of V1 is to drifting gratings with SF at 2.5-3 c/d (cycles/deg) (De Valois et al., 1982), rows of LGN cells corresponding to adjacent subregions should be separated by three-sixteenths to one-quarter degree [in particular, choosing ON/OFF pairs that are nearest neighbors, as proposed by Ringach (2007) and Paik and Ringach (2011), would lead to a quite different SF preference]; and (4) because of the limited reach of LGN axonal terminal trees (Angelucci and Sainsbury, 2006), a V1 neuron cannot be connected to LGN cells that have direct projections that are $>450 \mu \mathrm{m}$ away.

Permitting each cortical E cell to have 0-6 LGN inputs, arranged in two or three rows of one to three cells each, we found that constraints (1)-(4) above can be met by the LGN lattice in Figure $1 A$, but that there is only a small number of viable configurations. Some example LGN templates are shown in Figure 3. As shown in Figure $1 B$, we divided each HC into six distinct orientation domains, and stipulated that within each domain neurons received LGN inputs favoring one of the orientations of $0^{\circ}, 30^{\circ}$, $60^{\circ}, 90^{\circ}, 120^{\circ}$, or $150^{\circ}$, with $0^{\circ}$ taken to be vertical. Because the lattice we used has a threefold rotational symmetry, it is sufficient to enumerate two sets of admissible templates, one preferring, for example, horizontal and the other $30^{\circ}$ from horizontal. Rotating these two sets of templates by $60^{\circ}$ and $120^{\circ}$, one obtains templates for the other four orientations.

We used the following algorithm for assigning to each cortical neuron a set of afferent LGN cells: first pick the number of LGN inputs (nLGN) randomly according to a distribution the determination of which we postpone to the Modulation ratios and nLGN section below. Then, from the list of templates in the intended orientation of the cortical neuron and nLGN (Fig. 3), pick a template at random, with equal probability of picking templates with opposite polarity. Finally, go to the LGN sheet for the corresponding eye, and select a configuration of LGN cells matching this template, making sure that it projects to a location in cortex within $400-500 \mu \mathrm{m}$ of the cortical neuron in question.

Cells near the border of two orientation domains have positive probabilities of being assigned templates with either orientation. These probabilities are determined by a narrow Gaussian function: at $10 \mu \mathrm{m}$ from the boundary, the probability of picking the "wrong" template is 0.38 ; at $30 \mu \mathrm{m}$ away, the probability drops to 0.01 .

As for I cells, it does not matter a great deal whether one uses oriented or unoriented (or scrambled) LGN inputs. We have tried 


\section{A Vertical-preferring templates}

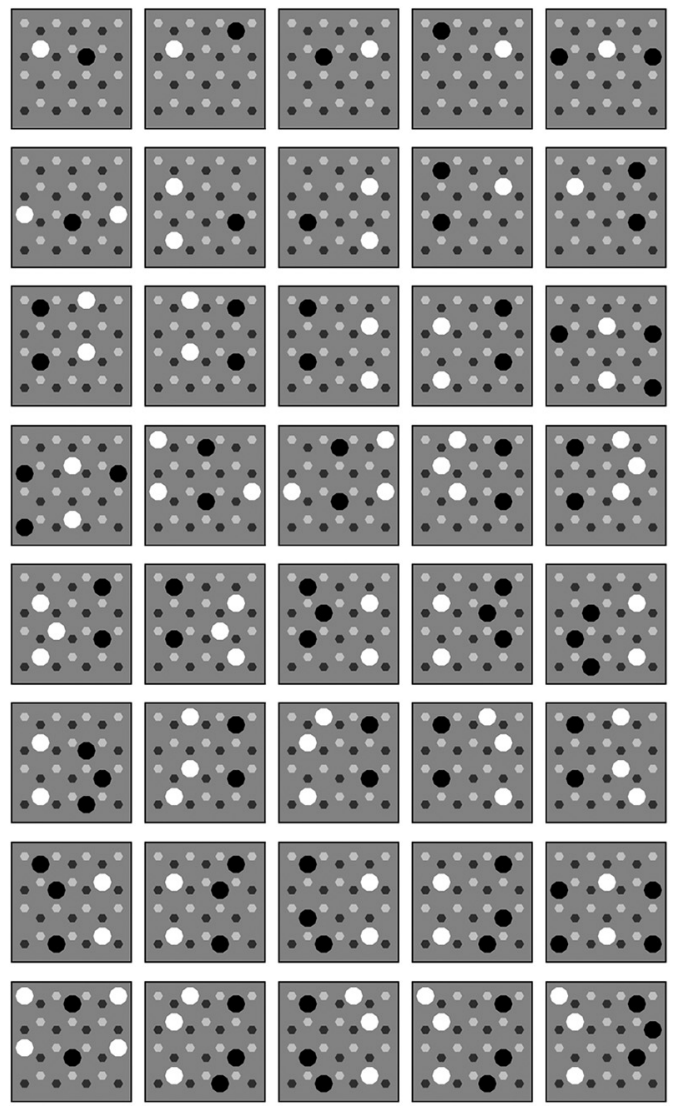

\section{B Horizontal-preferring templates}

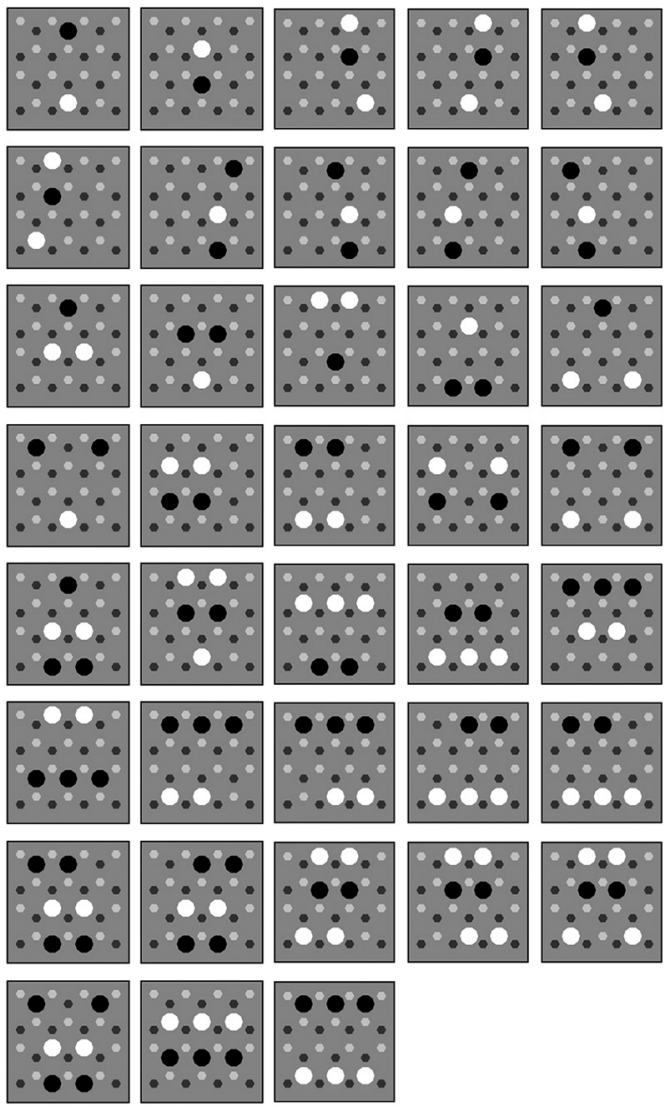

Figure 3. $L G N \rightarrow V 1$ connectivity. $A$, Templates of $L G N-V 1$ cell connections for excitatory cells in a vertical-preferring patch. All viable configurations of ON (white) and $0 F F$ (black) $L G N$ cells are enumerated, ordered by increasing numbers of cells in the configuration (nLGN). B, Templates for cells in a patch that prefers Horizontal orientation, ordered similarly. The model used templates for $0^{\circ}, 30^{\circ}, 60^{\circ}, 90^{\circ}, 120^{\circ}$, and $150^{\circ}$, obtained by rotating the two sets of templates shown.

both, and the results of model simulations were similar. In both cases, the I cells showed a significantly higher circular variance (CircVar) than E cells (see Results, Tuning and orientation-specific responses of model neurons), and the rest of the model was not substantially affected. In the simulations shown in this article, we used unoriented I cells, with nLGN ranging from zero to eight, its distribution given by a Gaussian with mean $=3, \mathrm{SD}=2$.

\section{Modulation ratios and $n L G N$}

We found that getting the model to match the distribution of the MR across the V1 population was a strong constraint on the number of LGN inputs (nLGN) and, therefore, on the allocation of LGN templates. The MR of the responses of a cortical cell has been taken to indicate the degree to which the cell sums its inputs linearly (De Valois et al., 1982; Skottun et al., 1991). Many experimentalists have measured MR and reported its diversity in V1 (Ringach et al., 2002). Here MR is defined to be $F_{1} / F_{0}$, where $F_{1}$ is the amplitude of the fundamental frequency of the response of the cell when it is driven periodically, and $F_{0}$ is the mean. Specifically, MR $=0$ corresponds to a cycle average that is constant over time; a sine wave function with amplitude equal to its average yields an $\mathrm{MR}=1$, and $\mathrm{MR}=2$ corresponds in practice to all spikes being concentrated in a single bin in each cycle average histogram. Following the studies by De Valois et al. (1982) and Skottun et al. (1991), we call a model cell "complex" if its MR is $<1$ when driven by its optimal grating at full contrast, and "simple" when MR is $>1$.

It is commonly thought-and receptive field mappings appear to support the hypothesis- that complex cells correspond to those V1 neurons with either no or few LGN inputs. In our model, such cells tend to be suppressed by cells with larger numbers of LGN afferents if nothing is done to boost their firing rates, yet it is an empirical fact that when driven, complex cells have firing rates that are higher than average [Ringach et al., 2002; http://www.ringachlab.net/lab/Data.html (the Ringach laboratory web site)]. This suggests that some boosting is necessary. We will return to this point later, preferring to first proceed to our main observation about the dependence of MR on nLGN.

With the firing rates of low nLGN cells adequately boosted (through increased connectivity or synaptic weights), we found that there is a strong correlation between the nLGN of a V1 cell and its MR. To illustrate this point, we presented the model with a battery of 64 gratings in eight different orientations, each with eight different SF values. In these model simulations of cortical responses, as for all of the other results of simulations in this article, the responses of the model were obtained for $20 \mathrm{~s}$ of visual stimulation. The MR of a cell was taken to be its MR for the grating to which it had the strongest response. When cells in the center HC of our model were divided according to nLGN and histograms of MR in each category were plotted, we observed a steady upward drift in MR as nLGN was increased. This phenomenon appears to be robust: it is independent of specific choices of parameters that affect mean firing rates (within a reasonable range) or of the allocation of nLGN among cells in the model.

Experimental results (Ringach et al., 2002; M. J. Hawken, unpublished observations) show that in layer $4 \mathrm{C} \alpha$ of the macaque 

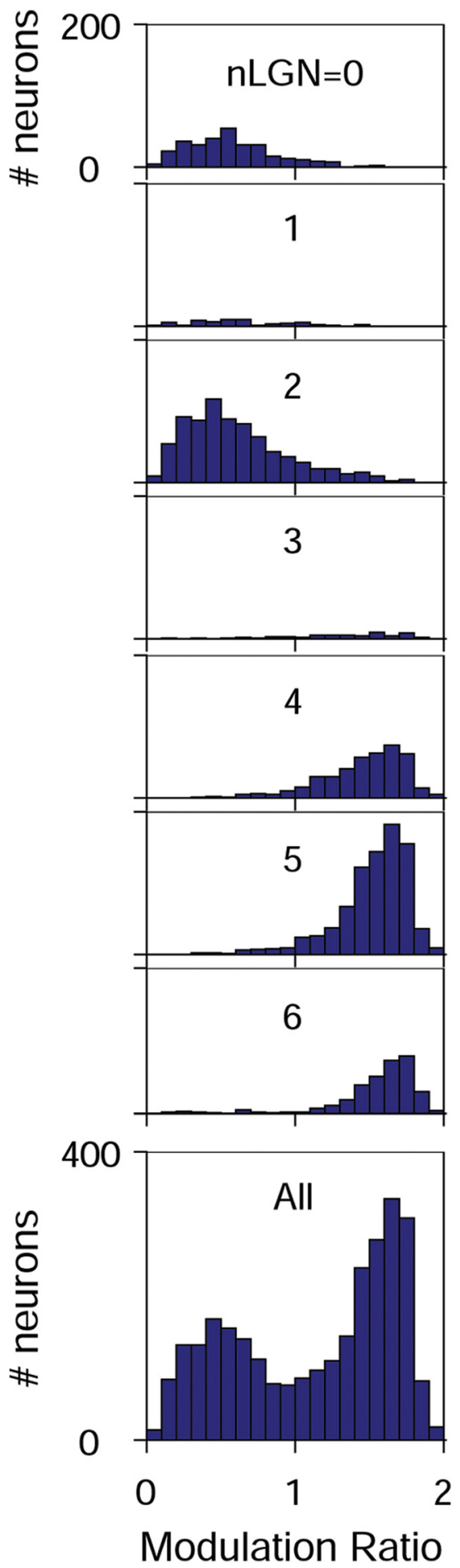

Figure 4. Number of $L G N$ inputs ( $(\mathrm{LGN})$ and modulation ratio (MR) distributions. Allocation of $n L G N$ inputs used in the model, chosen to produce a bimodal MR distribution that emulates data. Top seven panels, Histograms of MR in the central HC plotted in a vertical column separately for neurons with $\mathrm{nLGN}=0,1, \ldots, 6$. Bottom, Sum of the seven histograms yields the bimodal distribution of MR for all cells in the central HC.

V1 cortex, the distribution of the MR is bimodal, with $\sim 30 \%$ of the cells being complex. To carve out a bimodal distribution emulating data on relative incidence of simple/complex cells, we found it necessary to use nLGN distributions that approximately reflect these percentages, that is, to give approximately one-third of cortical cells zero to two LGN inputs, and approximately two- thirds of them, four to six LGN inputs. Using this as a guide, we located a range of nLGN distributions that emulate data, with some emulating data better than others.

The allocation of nLGN used in the model simulations presented is shown in Figure 4. Here complex cells correspond mostly to V1 cells with two LGN cells with ON-OFF pairs randomly oriented and positioned as close to one another as possible. We chose to give two LGN inputs to cells that would likely turn out to be complex because of the results of Hoffman and Stone (1971), Tanaka (1983), and Hirsch et al. (2003), who suggested that some complex cells have LGN inputs. However, others have reported no direct input of LGN to complex cells (Alonso et al., 2001). To find out whether or not it mattered that complex cells received $\mathrm{nLGN}=2$ or 0 , we also ran model simulations in which complex cells corresponded primarily to cells with $\mathrm{nLGN}=0$, and those simulations worked as well as the nLGN allocation scenario reported here.

We now return to the issue of firing rates. Other things being equal, driven firing rates in our model increase with increasing nLGN. This is reasonable, as V1 is a high-gain system and sensitivity to additional external drive is a hallmark of such systems. From the empirical fact that complex cells fire at a higher rate, we infer that some corrective mechanism is present. One possibility is that, via some form of homeostasis, neurons with less LGN input receive more excitation from other sources. We implemented this in the model: E neurons with fewer LGN inputs were given higher cortical input, from within $4 \mathrm{C} \alpha$ and L6. The idea of compensating a cell for low LGN inputs with higher cortical input was borrowed from the study by Tao et al. (2004), but, unlike the model in Tao et al. (2004), all of the neurons in our model receive most of their excitatory synaptic current from other cortical cells; therefore, the boosts of low nLGN cells are fractionally much smaller.

Specifically, the following enhancements in cortical inputs were used. Within layer $4 \mathrm{C} \alpha$, peak connectivity (as expressed in the number of presynaptic E neurons) ranged from $13 \%$ to $18 \%$, with lower corticocortical connectivity for cells with higher nLGN. Furthermore, V1 cells with zero to two LGN inputs had about twice as many presynaptic inputs from layer 6 as cells with five to six LGN inputs. Through exploration of many simulations, we found that the cortical enhancement of complex cells could be redistributed between $4 \mathrm{C} \alpha$ and L6, or between the amount of connectivity and synaptic weights, $S^{E E}$ and $S_{6}^{E E}$, as long as they produced the same combined enhancement of the firing rate.

The collection of templates in Figure 3 and the nLGN distribution in Figure 4 complete our model description.

Tuning and orientation-specific responses of model neurons Now comes the test: does our model perform like a real V1 cortex? To test the model, we used as visual stimuli sine gratings of high contrast, drifting at a rate of $4 \mathrm{~Hz}$, which is similar to stimuli used in many experimental studies of V1 function. The model data shown in Figures 5, 6, 7, 8, 9, and 10 are collected from the central HC (Fig. 1B, shading) to avoid boundary effects.

\section{Effectiveness of sparse LGN coding}

In the Introduction, we raised the issue of whether so few LGN inputs to a V1 HC can confer OS on V1 neurons. Indeed, there is reason for concern: from Results, Input patterns of LGN to V1 (Fig. 4), the number of LGN inputs to a cortical neuron is, on average, $\sim 4$ compared with $\sim 200$ presynaptic E neurons from layer $4 \mathrm{C} \alpha$, and $30-50$ presynaptic E neurons from L6. Even with 


\section{A Excitatory cells}
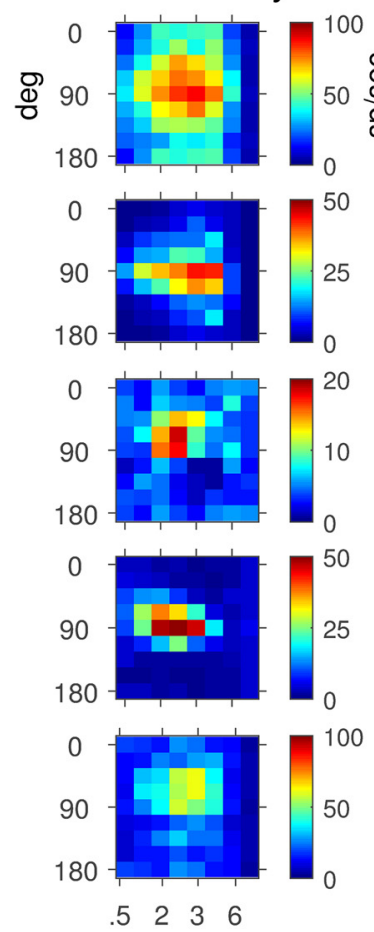

$\mathrm{c} / \mathrm{d}$
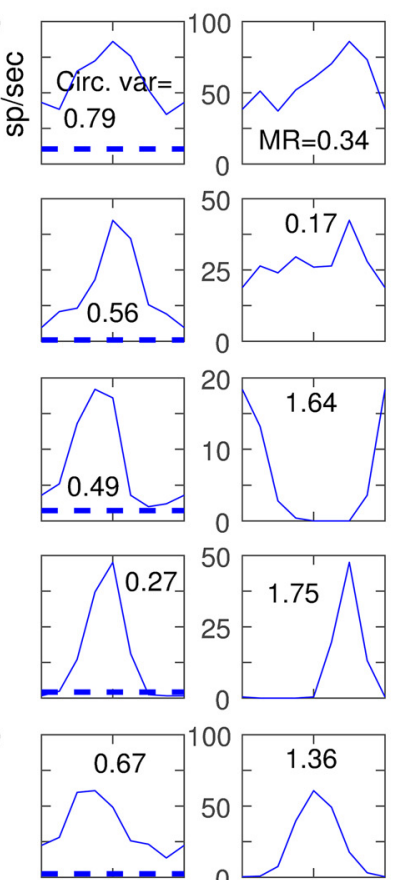

$\begin{array}{lllll}90 & 180 & 0 & 125 & 250 \\ \text { deg } & & & & \\ m s\end{array}$

\section{B Inhibitory cells}

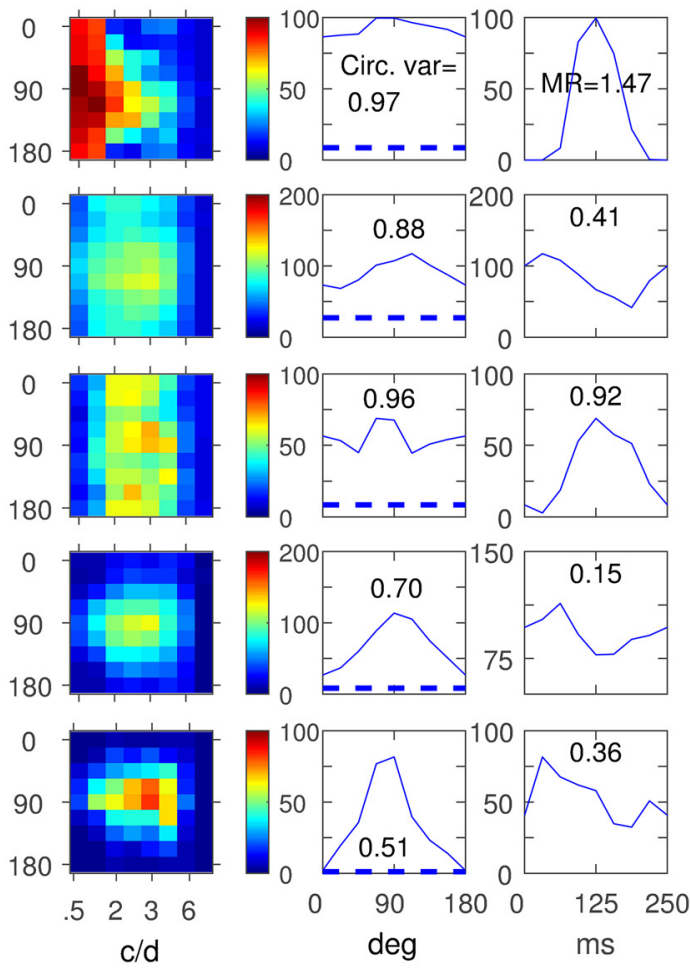

Figure 5. Orientation and SF tuning in the model. $A$, Five E cells from the horizontal $\left(90^{\circ}\right)$ patch of the central $\mathrm{HC}$, driven at $4 \mathrm{~Hz}$ by a battery of gratings at $100 \%$ contrast. Left, $<0$ rientation, spatial frequency $>$ matrix of peak responses. Middle, Orientation tuning curves with CircVar values displayed. Right, Cycle average firing rates with MRs. $\boldsymbol{B}$, Five I cells from the same patch as in $\boldsymbol{A}$, and their peak responses, orientation, and spatial frequency tuning as illustrated in $\boldsymbol{A}$. The dashed horizontal lines indicate the mean background firing rates.

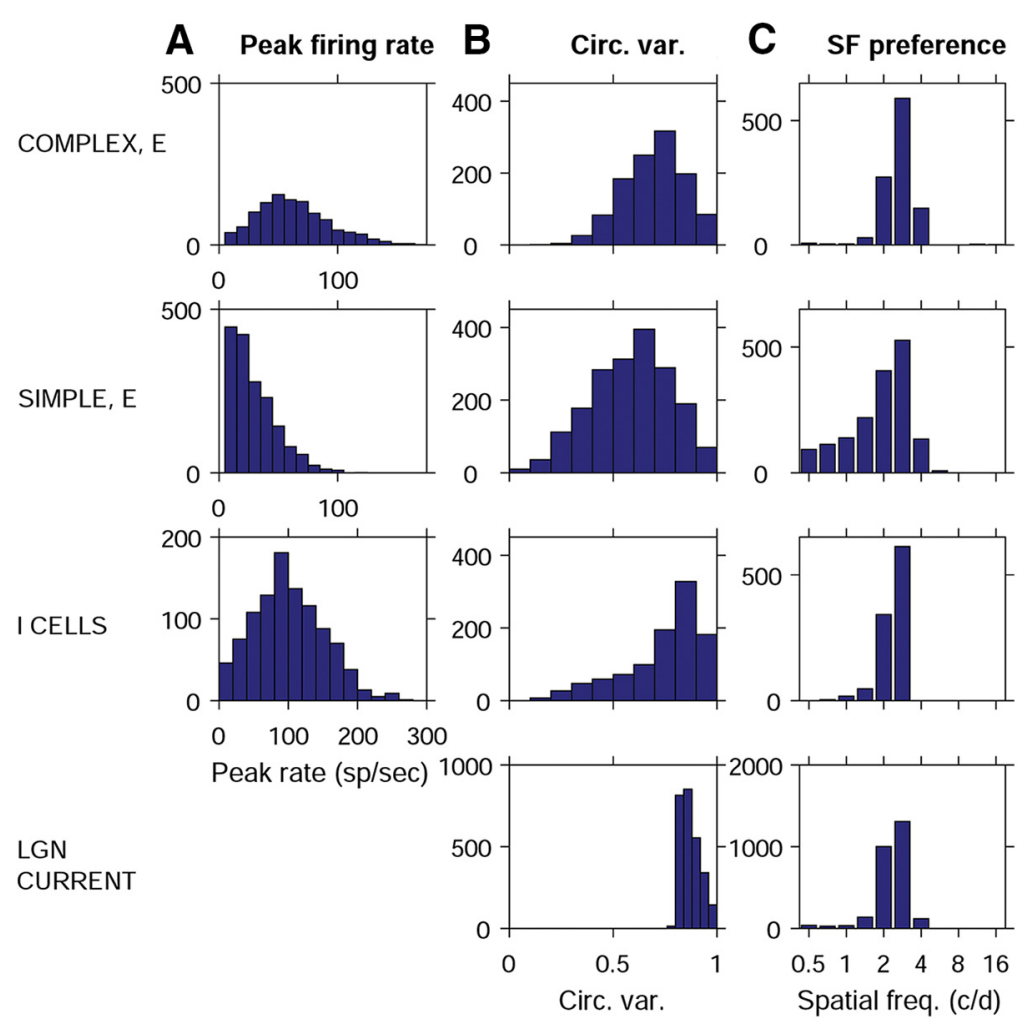

Figure 6. Histograms of firing rates, orientation, and spatial frequency tuning in the central HC. The top three rows show histograms for excitatory complex cells, excitatory simple cells, and inhibitory cells. Bottom row shows distributions of CircVar and of the SF preference of the synaptic current from LGN to all E cells. (No meaningful notion of firing rate distribution for LGN current.)
$S^{E, \mathrm{LGN}} \sim 2 * S^{E E}$ and driven LGN firing rates approximately three times that of cortical neurons, the fraction of input currents to a $4 \mathrm{C} \alpha$ neuron that is feedforward is small-in fact the simulations indicate that the excitatory drive from LGN is $<20 \%$ of the total in simple cells, and $<10 \%$ in complex cells.

Nevertheless, the model produces model $\mathrm{E}$ cells with the range of properties expected from experimental data. Figure 5 shows the OS properties of example neurons from the model. The color maps in Figure $5 A$ show the responses of five representative model $\mathrm{E}$ cells from a horizontal-preferring patch. Their responses, measured in terms of peak firing rates, are to an orientation $\times$ SF matrix of gratings (De Valois et al., 1982), with orientation plotted on the vertical axis and SF on the horizontal axis. The eight orientations range between $0^{\circ}$ and $180^{\circ}$ evenly spaced, and the eight $\mathrm{SF}$ values range from 0.5 to $16 \mathrm{c} / \mathrm{d}$. In the middle and right columns are the tuning curves and cycle average firing rate distributions of the same neurons.

The five E neurons shown in Figure 5 have peak firing rates ranging from 20 to $80 \mathrm{spikes} / \mathrm{s}$, and they have quite varied tuning curves and profiles of cycle aver- 


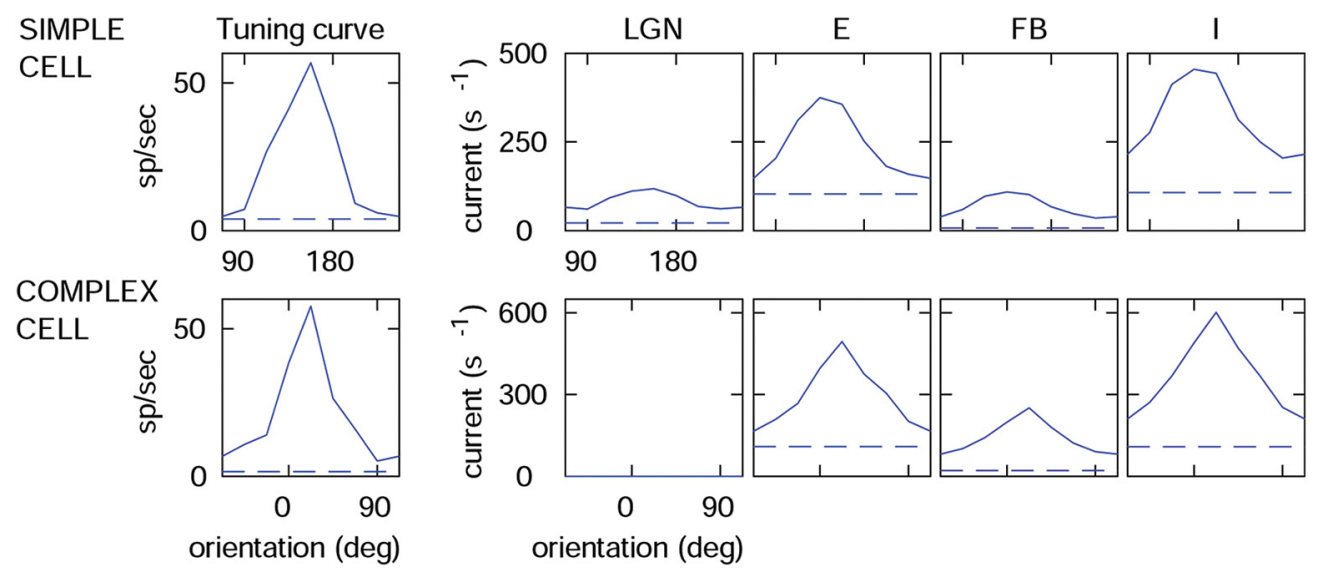

Figure 7. Orientation tuning curves of two representative model E cells and their synaptic inputs. The orientation tuning of the peak of the averaged response is plotted vs orientation. Top row, A simple E cell; bottom row, a complex E cell. Both cells are drawn from the same vertical-preferring patch of model $4 C \alpha$. Tuning curve, Orientation tuning of the spike rates of the cells (the E cells have CircVar 0.5); LGN, LGN input current as a function of orientation angle; $\mathrm{nLGN}=5$ for the simple cell and $\mathrm{nLGN}=0$ for the complex cell (i.e., the complex cell illustrated here receives zero $\mathrm{LGN}$ input current). The three panels on the right show input currents from various sources as functions of orientation. E, Recurrent cortical excitatory current; $F B$, cortical feedback excitatory current (from layer 6); I, cortical inhibitory current. Note that the inhibitory current is plotted as positive in magnitude, but its sign is opposite to that of the excitatory currents.

ages. If one compares these tuning curves to those of real V1 neurons (Ringach et al., 2002), one finds that model E cells have as much OS as in real cortex, with the same diversity: some of the model neurons are highly selective, while others have broad tuning curves.

Figure $5 B$ demonstrates that model I cells are less selective for orientation than E cells. Though they show some selectivity, the five representative model I cells produce $<$ ori, SF $>$ response surfaces that are markedly less peaked than those of E cells (Nowak et al., 2008).

The model allows us to analyze OS across the population. Next, we present model population statistics, collected from the central HC of our nine-HC model cortex (Fig. 1B).

\section{Firing rates}

To demonstrate that the model emulates V1, we present in Figure $6 A$ the peak firing rates of model neurons when driven by their preferred gratings (from among the 64 used for the simulations depicted in Fig. 5). The distributions in Figure 6A, which show complex E cells firing more than simple E cells (D. Ringach, R. M. Shapley, and M. J. Hawken, unpublished observations), and I firing rates three to five times those of E firing rates (Swadlow, 1988; Cardin et al., 2007), are consistent with data.

We also call attention to the wide range of firing rates seen in Figure $6 A$. The diversity of neuronal responses resembles what is found in V1 (Ringach et al., 2002) and is an emergent property in the model, meaning it is a property that was not programmed into the equations governing the dynamics of individual neurons (see Materials and Methods, Equations of neuronal dynamics) but occurs as a result of interactions among neurons. Analysis revealed the source of the observed diversity as caused by the fact that small random biases in connectivities and synaptic weights are magnified through neuronal interactions, exaggeratingthrough recurrent inhibition-the dominance of neurons that receive slightly more E input or slightly less I input. Competition among neurons drives much of the dynamics in this model, and we propose that the same may be true in the real cortex, as indicated by the data from the study by Monier et al. (2003).

\section{Circular variance}

Circular variance (CircVar) is a widely used measure of OS (Mardia, 1972; Batschelet, 1981; Ringach et al., 2002). CircVar $=1$ for nonselective neurons, and CircVar $=0$ for perfectly selective neurons. As one can see in Figure $6 B$, the mean CircVar for E neurons is between 0.6 and 0.7 , which is in agreement with data. Equally if not more striking are the spreads of the distributions of CircVar in the model. They show great diversity: some neurons are very broadly tuned, while others are quite sharply tuned. Such diversity is also characteristic of real V1: both mean and variance are consistent with experimental data (Ringach et al., 2002; Zhu et al., 2010). As with firing rates, diversity in CircVar in the model is due in part to the probabilistic connectivity between cortical cells (Fig. 1C,D).

Model I cells have some but significantly less OS (higher CircVar) than E cells, which is also consistent with available data (Nowak et al., 2008). Among the reasons why I cells in the model are less tuned than E cells even though they receive excitatory input from a comparable region of the $\mathrm{HC}$ (Fig. $1 C, D$ ) may be (1) that I cells receive unoriented LGN inputs, and (2) suppression of responses to the orthogonal-to-preferred orientation has a stronger effect on E cells than on I cells because $S^{I I}$ is smaller than $S^{E I}$.

Least tuned of all are LGN input currents to cortical cells, with a CircVar of $\sim 0.8-0.9$; this is discussed in more detail in conjunction with Figure 7.

Bandwidth is another measure of OS that is widely used (De Valois et al., 1982). We calculated bandwidth distributions for model neurons (simulation results not shown) and found very good agreement quantitatively, both in mean values and in the variance, with experimental data (De Valois et al., 1982; Ringach et al., 2002).

\section{SF preferences}

Histograms of SF preferences are shown in Figure 6C. As is consistent with data (De Valois et al., 1982), the overall preferred SF is $2-3 \mathrm{c} / \mathrm{d}$. This property is effectively built into the model by the spatial frequency tuning function for LGN cells (Materials and Methods, Equations of neuronal dynamics; Zhu et al., 2010) and the distances between ON and OFF subregions in the LGN templates (Figs. 1, 3). Model complex cells prefer a slightly higher SF due to the geometry of their LGN afferents: tightly packed two LGN cells respond better to slightly higher SF (see Results, Input patterns of LGN to V1). This model result also is consistent with data from the study by De Valois et al. (1982). 
A

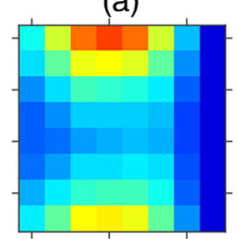

(d)

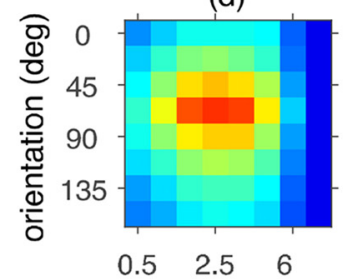

spatial frequency $(\mathrm{c} / \mathrm{d})$ (b)

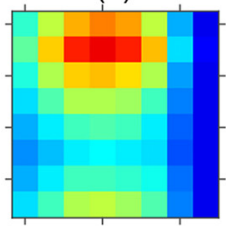

(e)

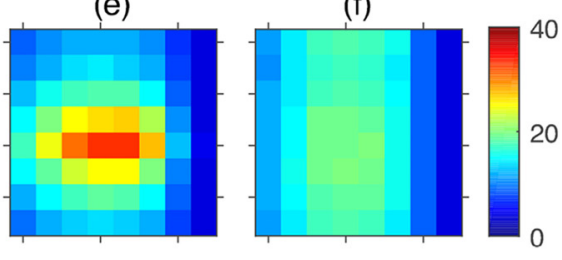

(c)

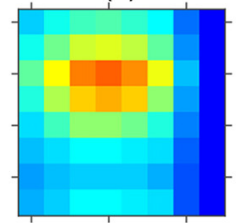

(f)
Patch locations
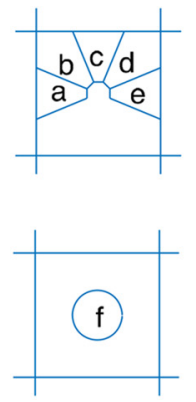

B
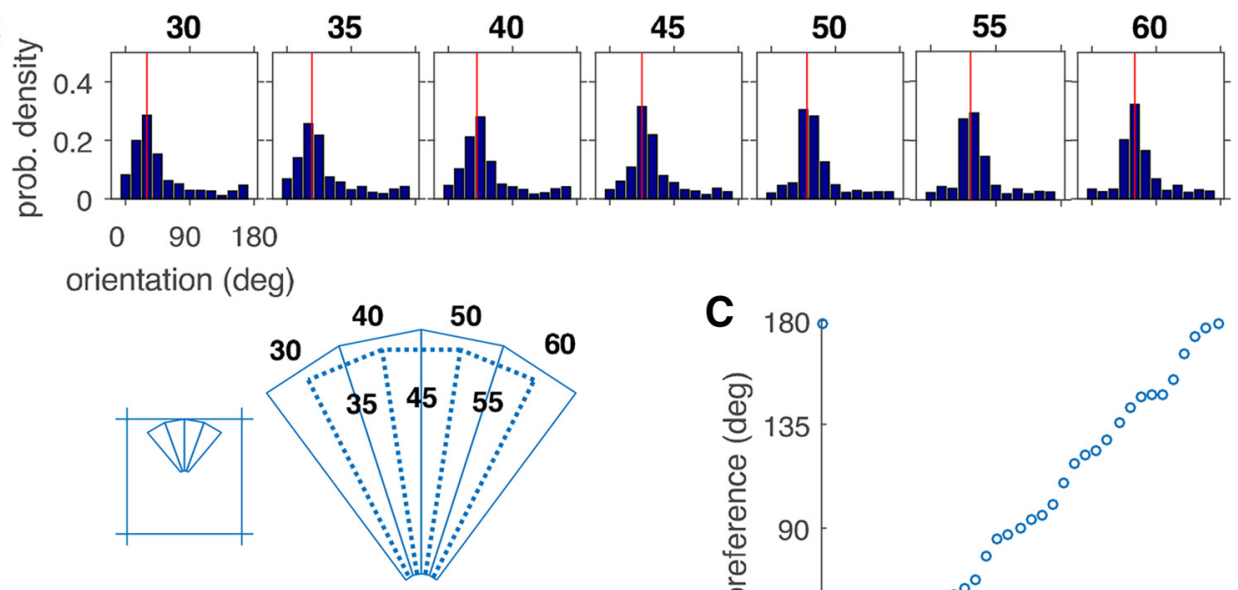

Patch locations

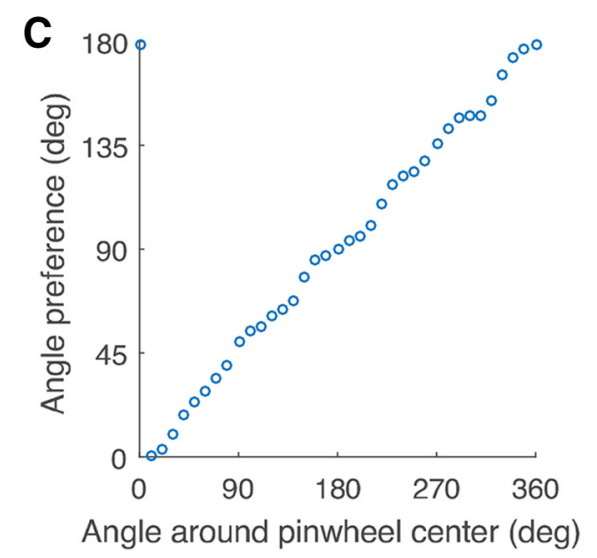

Figure 8. Continuity of orientation maps. A, Patch-averaged peak firing rates for E cells as a function of spatial frequency and orientation. The first five panels are for patches preferring $0^{\circ}, 22.5^{\circ}$, $45^{\circ}, 67.5^{\circ}$, and $90^{\circ}$; the sixth panel is located at the pinwheel center. The sizes and locations of these patches in the central HC are indicated (right). The grid square of each color map denotes a grating with specified orientation and SF; its color corresponds to peak rates averaged over all $E$ cells in the patch. $\boldsymbol{B}$, The seven panels show distributions of orientation preferences for patch neurons in seven wedges in the central $\mathrm{HC}$ corresponding, in an ideal orientation map, to regions preferring $30^{\circ}, 35^{\circ}, 40^{\circ}, \ldots, 60^{\circ}$, respectively (see main text and inset for detail). The histograms depict responses to 12 gratings $5^{\circ}$ apart between $0^{\circ}$ and $180^{\circ}$. The red vertical line in each plot denotes the hoped for average orientation preference. C, Plot of average visual angle preference as a function of angle around the pinwheel center.

Sources of input currents to a cortical cell

Having established that our model neurons enjoy OS, we now analyze the model to understand how it came about. Figure 7 displays the tuning curves of spike rates and currents that go into two typical cortical neurons, one simple E cell and one complex E cell that were chosen to have approximately the same moderate amount of OS (CircVar $\sim 0.5)$. The top row of Figure 7 shows information for the simple cell. Its orientationtuning curve for peak spike rate is plotted in the leftmost panel of Figure 7. The graph labeled "LGN" shows its summed LGN input current at the peak of the cycle-averaged response. LGN current is only weakly OS, which is consistent with the statistics in Figure 6. Weak OS of LGN input in our model is not surprising: given that the RF subregions in our LGN templates are so short and so far apart (Fig. 3), an LGN configuration of, say, 3-ON, 2-OFF responds to gratings of many different orientations. The improvement in OS is caused by a combination of the strong effect of tuned recurrent excitation from neighboring E cells (Fig. 7, panel labeled "E") that have spike ratetuning curves like the tuning curve displayed on the left, and the effect of recurrent inhibition (Fig. 7, panel labeled "I"), which tends to suppress responses at nonpreferred orientations (Zhu et al., 2010; Xing et al., 2011). OS is further enhanced by cortical dynamics, by the temporal synchronization of recurrent excitation (Fig. 9). In addition, feedback from L6 (Fig. 7, "FB") slightly augments OS.

The bottom row in Figure 7 shows the corresponding plots for a complex cortical neuron with $\mathrm{nLGN}=0$ and low MR. We have chosen such a cell to illustrate the point that, even with no direct LGN input, a cell can acquire OS from neighboring cells via corticocortical interactions. One can observe in this case the strong, tuned, recurrent excitatory drive from neighboring E cells (Fig. 7, panel labeled "E"). We point out that ours is the only realistic 
model of the visual cortex that provides a robust mechanism for OS in complex cells. Complex cells in the Tao et al. $(2004,2006)$ and Zhu et al. (2010) models did not have much OS, and in those of McLaughlin et al. (2000) and Wielaard et al. (2001) there were no complex cells to speak of.

To summarize, our model shows that to cultivate a property like OS it is necessary only to "seed" it, that is, to introduce a weak form of OS to a fraction of the population (e.g., those cortical cells with four or more LGN inputs), and the effects will be amplified through corticocortical interactions. Similar views have been expressed before (Ben-Yishai et al., 1995; Hansel and Sompolinsky, 1997). Here we demonstrate the idea in a realistic model, with robust OS in both simple and complex cells emerging as a result of corticocortical interactions.

\section{Continuity of orientation maps}

An important question raised in the Introduction is whether or not the model can generate orientation preferences that are intermediate between the small number of orientations that can be specified by the known sparse LGN connectivity. Simulation results, using the same $8 \times 8$ matrix of $<$ orientation $\times$ $\mathrm{SF}>$ gratings as in the results shown in Figure 5, answered this question in the affirmative (Fig. 8). In the <orientation $X$ $\mathrm{SF}>$ matrix, we deliberately used grating orientations that were not commensurate with those in the LGN templates (Results, Input patterns of LGN to V1). The templates have a threefold rotational symmetry, while the gratings used in the experimental simulations represent eight orientations at equal angles apart. Figure $8 A$ shows the peak firing rates in response to the $<$ orientation $\times \mathrm{SF}>$ matrix averaged over several hundred neurons in six different patches, the precise locations of which in our model cortex are also shown. Except for the pinwheel-center patch, each of the other patches shows a clear preference for an orientation and a range of SF values. The orientation preference coincides with the location of the patch within the HC, and the SF preference peaks at $2-3 \mathrm{c} / \mathrm{d}$, consistent with macaque V1 data (De Valois et al., 1982). Since no cortical cell has LGN afferents aligned with grating stimuli at $45^{\circ}$ or $135^{\circ}$, the only way that some neurons can acquire orientation preferences in these directions is through the effects of corticocortical interactions.

To take a closer look at the ability of our model to produce orientation preferences not represented by LGN templates, we focus on two adjacent regions of the HC, one containing neurons assigned LGN templates aligned with $30^{\circ}$, and the other templates aligned with $60^{\circ}$; the two regions are separated by a narrow corridor in which some neurons receive the $30^{\circ}$ and some the $60^{\circ}$ templates (see Results, Input patterns of LGN to V1). The question of interest here is, how well can the model "see" the visual angles in between?

Figure $8 B$ shows statistics for orientation preferences when the model is presented with 12 gratings, aligned with orientations evenly spaced between $0^{\circ}$ and $180^{\circ}$. The seven panels show histograms of preferences for neurons located in seven different (narrow) wedges of the $\mathrm{HC}$, chosen so that, with an ideal orientation map, they would have orientation preferences for $25-35^{\circ}$, $30-40^{\circ}, 35-45^{\circ}, \ldots, 55-65^{\circ}$, respectively. In the first and last panels, it is not surprising that $30^{\circ}$ and $60^{\circ}$ are preferred, given that they coincide with LGN template assignments. But observe how, in increments of 5 visual degrees, the peaks of the histograms shift gradually yet definitively to the right. In the third panel of Figure $8 B$, for example, all of the neurons receive $30^{\circ}$ templates, yet, due to their relative proximity to the $60^{\circ}$ region there is an unmistakable bias in that direction. Neurons in the fourth panel of Figure $8 B$ have the strongest preference for $45^{\circ}$, even though there are no $45^{\circ} \mathrm{LGN}$ templates. The only way that these graded preferences could come about is through corticocortical interactions.

Notice also the diversity in preferences within each region in Figure $8 B$. While the neurons collectively have a clear orientation preference, individually they show great diversity in their preferences. Many cells deviate significantly from the mean of the local population. The diversity of orientation preference is also an emergent property; it comes about as a consequence of the biases in cortical input coupled with the dominance of recurrent and feedback excitation in the model. These features depend on the probabilistic connectivity between cortical cells described in Figure $1, C$ and $D$.

Further evidence of smoothing of the orientation map is displayed in Figure $8 C$, which plots vector means of the most preferred orientations for 36 wedges organized around the pinwheel center of the HC. Each wedge spans $10^{\circ}$ in visual angle with overlapping windows, as in Figure $8 B$. Evidently our model network was able to smooth out the very sparse information passed along by LGN to create a continuous orientation map without abrupt jumps in orientation preference that might be expected from the sparse LGN input alone.

\section{Robustness of OS}

The simulation results in this article assume that $S^{E, \mathrm{LGN}}=2.1$ * $S^{E E}$ following the study by Stratford et al. (1996); see Materials and Methods, Parameter determination. Other articles have reported different ratios of thalamocortical-to-corticocortical synaptic strength; e.g., it was found to be $\sim 1$ for cat S1 (Schoonover et al., 2014) and $\sim 4$ for mouse S1 (Gil et al., 1999). Therefore, we thought it was necessary to explore whether or not varying the $S^{E, \mathrm{LGN}} / S^{E E}$ ratio would affect OS adversely, and found that it does not. With other parameters set to be similar to those in the present model, we found that setting $S^{E, \mathrm{LGN}} / S^{E E}=1$ causes firing rates to decrease and the fraction of complex cells to increase, and vice versa when $S^{E, \mathrm{LGN}} / S^{E E}=3$. However, when suitably rescaled, the orientation tuning and orientation maps, as shown in the plots in Figure $8 A$, remain substantially unchanged. This proves that OS is extremely robust in this kind of model with approximately balanced excitation and inhibition.

\section{Temporal dynamics in background and under drive}

The dynamics of spike firing in local populations is a crucial emergent property of the model that makes a significant contribution to OS. Raster plots of spike firing in $500 \mathrm{~ms}$ windows are shown in Figure $9 B-D$, for a patch of $\sim 400 \mathrm{E}$ and I neurons in an orientation domain. Figure $9 B$ depicts spike firing in background, and Figure $9 C$ when the population is driven by a grating drifting at the optimal orientation, while Figure $9 D$ shows how the same population responds to a grating drifting at the orthogonal-to-preferred direction. Notice the gamma rhythm $(25-90 \mathrm{~Hz})$ due to partial synchronization in the spike firing in Figure $9 \mathrm{C}$. The periodicity of the visual drive $(4 \mathrm{~Hz})$ can be deduced from Figure $9 A$, which shows the spike firing of a target $\mathrm{E}$ cell and its four LGN inputs. Observe by comparing panels $A$ and $C$ in Figure 9 that gamma rhythms are tied neither to the spiking of LGN cells, which can fire at considerably higher rates $(\sim 100$ spikes/s), nor to the much slower temporal frequency of the drifting grating; they are generated within cortex with their own autonomous resonant frequencies. This is an emergent property of population activity. 
A

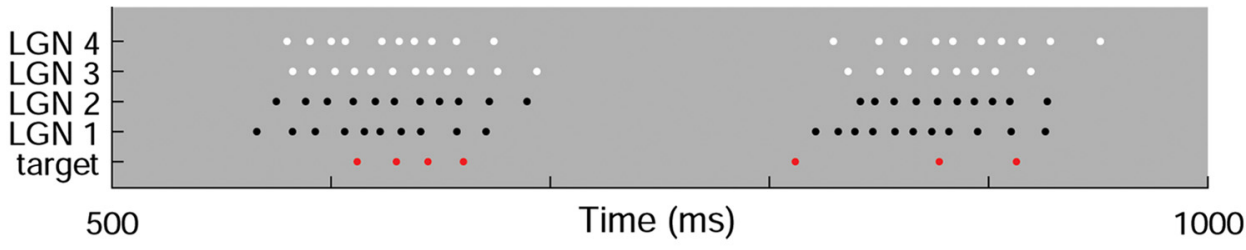

B

Background; E rate $=3.7 \mathrm{sp} / \mathrm{sec} ;$ I rate $=13 \mathrm{sp} / \mathrm{sec}$

B

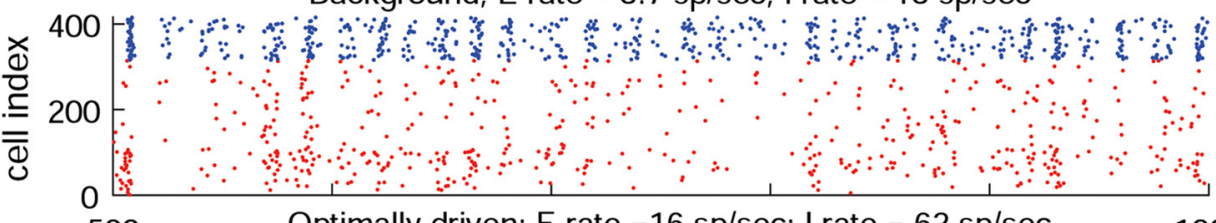

C

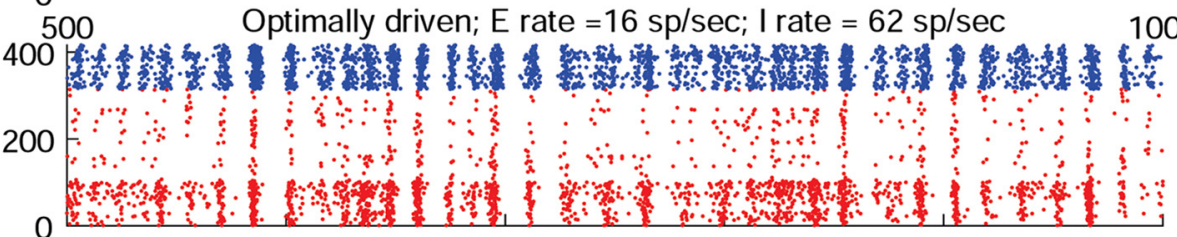

D
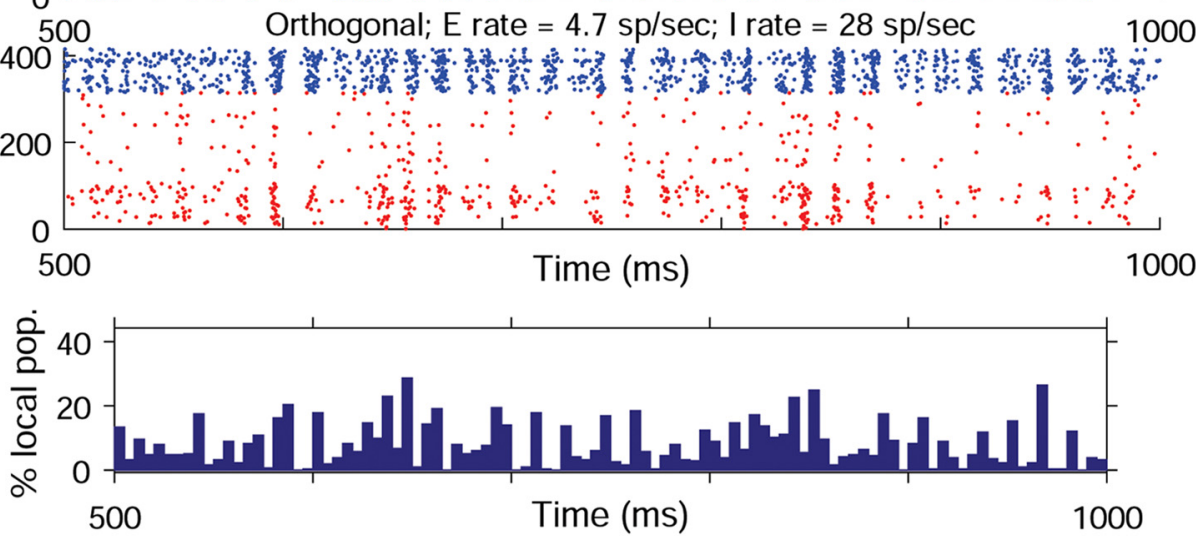

E
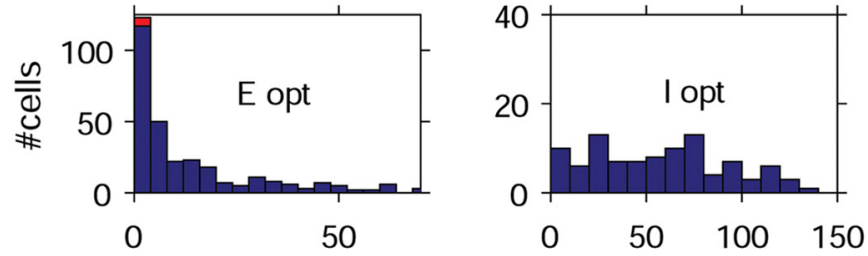

Firing rate $(\mathrm{sp} / \mathrm{sec})$

Figure 9. Dynamics of $\mathrm{V} 1$ population impulse trains and mean firing rates. $A$, Rasters of spikes of a target $\mathrm{V} 1 \mathrm{E}$ cell and its four $\mathrm{LGN}$ inputs. These are responses to an optimal drifting grating, drifting at $4 \mathrm{~Hz}$ (250 ms period). White dots, $0 \mathrm{~N}$ center $\mathrm{LGN}$ spikes; black dots, $0 \mathrm{FF}$ center $\mathrm{LGN}$ spikes; red dots, $\mathrm{V} 1$ spikes. $\boldsymbol{B}-\boldsymbol{D}$, Rasters of background spike firings in the cortical patch that prefers vertical gratings in the central $\mathrm{HC}(\boldsymbol{B})$; rasters when the same patch is driven at the optimal (vertical) orientation of the patch $(\boldsymbol{C})$, driven by the orthogonal orientation $(\boldsymbol{D}) . \boldsymbol{B}$ - $\boldsymbol{D}, x$-axis is time; $y$-axis is neuron index within the patch, sorted by number of LGN inputs; lower indices correspond to fewer LGN inputs. E cell spikes are red dots; I cell spikes are blue dots. $\boldsymbol{E}$, Further information for the regime depicted in C. Top, Summed spike activity of the E population as a function of time, shown in $5 \mathrm{~ms}$ windows. The vertical scale of the plot is the fraction of the total number of cells, illustrating that, in what may appear to be synchronous spiking events in $C$, only a small fraction of all $E$ cells are active. Bottom panels, Histograms of mean firing rates in impulses per second for $E$ and I neurons in the same patch, driven in the optimal orientation.

In our model, synchronization of spike firing in the gamma band is graded and depends on stimulus orientation. These results are consistent with experimental data (Eckhorn et al., 1988; Gray and Singer, 1989; Volgushev et al., 2002; Kayser and König, 2004; Henrie and Shapley, 2005; Womelsdorf et al., 2012). The Fourier transform of the summed spike density of the neurons (data not shown) has a gamma peak that was high and narrow for the optimal stimulus, weaker and broader for the nonpreferred stimulus, and low and very broad under background conditions. Not only is the greater synchronization at the preferred orientation an orientation-specific response, it contributes to OS by amplifying the effect of recurrent excitation locally.
It is important to emphasize that, unlike the PING model (Whittington et al., 2000), synchronization events in our model involve only fractions of the population, and participation varies widely from neuron to neuron. The wide distribution of model firing rates shown in Figure $9 E$ does not support synchronous spiking involving the full population. Notice in fact that most model neurons fire at rates too low to follow the gamma-band fluctuations. In this respect, the firing rate distributions of the model resemble many experimental datasets (for review, see Roxin et al., 2011; Buzsáki and Mizuseki, 2014; M. J. Hawken and R. Shapley, unpublished V1 observations). Even though it may appear from the raster plot in Figure $9 C$ that the population firing is highly synchronous, only a fraction of the population partici- 


\section{A Simple E-cell}

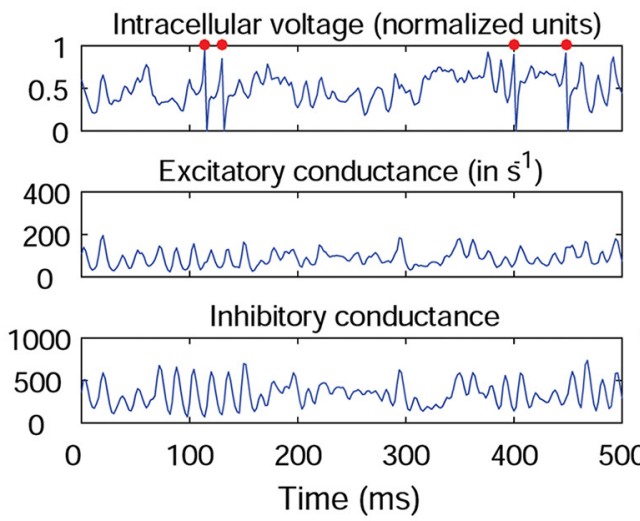

B Complex E-cell
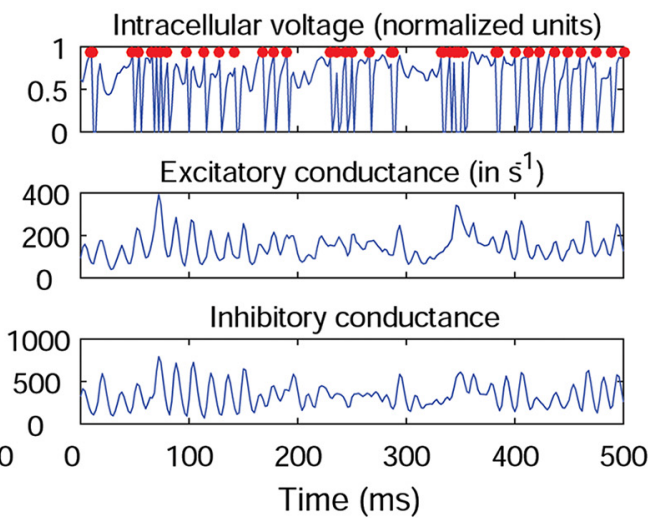

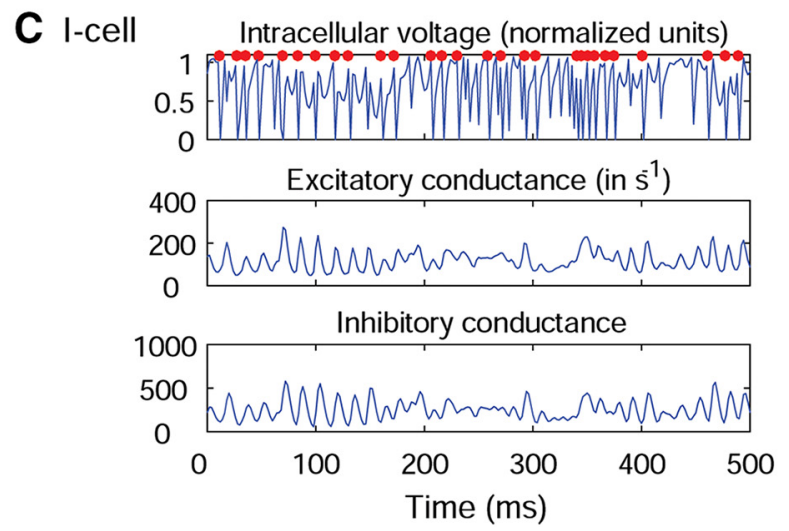

Figure 10. Intracellular voltages and conductances of driven E and I cells. $\boldsymbol{A}$, Intracellular voltage [in normalized units $(0,1)$; see Materials and Methods, Equations of neuronal dynamics], $E$ conductance, and I conductance for one representative simple E cell in the vertical patch (as in Fig. 9). $\boldsymbol{B}$, Same for one representative complex E cell in the patch. $\boldsymbol{C}$, Same for one representative I cell in the same patch. 0 ccurrences of spikes indicated by red dots in the voltage plots.

pates in any firing event. Figure $9 E$, which gives the spike counts for E neurons in Figure 9C, shows clearly that no more than 25\% or so of the E population fire spikes in any of the $5 \mathrm{~ms}$ windows.

For a general discussion of the dynamic mechanism behind such partial synchronization in neuronal networks, see the study by Chariker and Young (2015). Gamma rhythms are very important signatures of cortical dynamics, but in the interest of limiting the length of this article, we have elected to postpone a more detailed analysis to a forthcoming article.

To elucidate how gamma-band rhythms are related to the dynamics of individual neurons, we show in Figure 10 the voltage and conductance traces of three model neurons: two E cells, one simple and one complex (Fig. 10A,B); and an I cell (Fig. 10C). These traces strongly resemble data from intracellular recordings (Hasenstaub et al., 2005). Figure 10A-C show that fluctuations in conductance are entrained to gamma-band fluctuations, even though most of the rising peaks do not cause spikes to fire. Indeed, how often a neuron spikes, and when, is to some degree accidental, depending on whether a threshold is crossed. And that in turn has to do with the interplay between the $\mathrm{E}$ and I populations, even the arrival times of the spikes of presynaptic E/I neurons. Figure 10 demonstrates clearly that firing rates are determined by dynamics, and cannot be computed from the LIF equations and parameters alone, i.e., they are also emergent properties of the model.

\section{Model predictions}

A fraction of the simulation results we presented was for purposes of validating the model by comparison with existing data. Among the many model outputs that compare well with existing data are background and driven firing rates and their distributions (Figs. $2,6,9$ ), modulation ratio (Fig. 4B), orientation and spatial frequency tuning of individual E and I cells (Fig. 5), population statistics on peak firing rates, CircVar and SF distributions (Fig. 6), and gamma-band synchronization that is somewhat tuned for orientation (Fig. 9).

A number of our model results go beyond the data that are currently available. We propose them as model predictions to be tested in future experiments, as follows.

(1) Configurations of LGN cells presynaptic to cortical E cells, as proposed in Results, Input patterns of LGN to V1 (Fig. 3).

(2) Weak OS of I cells: there are some data about weak OS of I cells in cat cortex (Nowak et al., 2008) and also in mouse visual cortex (Isaacson and Scanziani, 2011; Liu et al., 2011), but quantitative data about the distribution of OS in I cells are lacking.

(3) The even weaker OS of LGN input currents to a cortical cell: data about mouse V1 indicate very weak OS of LGN input to V1 cells (Lien and Scanziani, 2013); LGN input to V1 in macaque is likely very different from that in mouse, but the model predicts that its OS also is very weak, as shown in Figure 6.

(4) The sharpening of OS for $4 \mathrm{C} \alpha$ cells through interaction with other cortical neurons, with or without direct LGN input, as shown in Figure 7.

(5) Properties of the HC orientation preference map: robust population averages vs the diversity of responses among individual neurons revealed in Figure $8, A$ and $B$.

(6) The continuity of orientation preference maps, as depicted in Figure $8 C$ (the present resolution of optical imaging is not 
sufficient to test predictions 5 and 6 , and high-resolution measurements with two-photon imaging or another high-resolution technique will be needed).

(7) The partial participation of individual cells in gamma rhythms, as evidenced by the irregular spiking and entrainment of the conductances shown in Figures 9 and 10. While some intracellular recordings in V1 in vivo (Volgushev et al., 2002) suggest the intermittent participation in the gamma rhythm that the model predicts, more data are needed to test this specific prediction.

What distinguishes our model from feedforward (or modified feedforward) models (e.g., Priebe and Ferster, 2008; Persi et al., 2011; Rubin et al., 2015; Goris et al., 2015) are the model predictions we have to offer. Predictions such as the sharpening of OS, higher OS in E cells than I cells, smooth orientation maps on fine spatial scales, orientation-tuned gamma synchronization, and diversity of OS and orientation preferences within local populations are based on model phenomena that emerge as a result of dynamic cortical interactions. Feedforward models, which downplay dynamic interactions, generally do not enable such predictions.

\section{Discussion}

The ability of the model cortex to (1) sharpen weakly tuned orientation inputs (Figs. 5, 6, 7) and (2) fill in the gaps of orientations not represented by LGN (Fig. 10) is very strong evidence in support of the hypothesis that, although visual signals in the brain originate from the retina and LGN, dynamic interactions of cortical neurons play a major role in the processing of this information. In our model, OS is extremely robust, and does not require any fine-tuning of parameters as long as excitation and inhibition are roughly balanced.

\section{How does the model work and what insight does this give us into cortical function in general?}

Much of the visual processing leading to OS occurs within the cortex as a result of the dynamic interactions among cortical neurons. Therefore, these dynamic interactions are a focal point of our investigation. We have seen in Results (Tuning and orientation-specific responses of model neurons) how, through recurrent excitation, cortex produces a coherent and robust orientation preference in local populations, derived from "seeds" of orientation bias transmitted through weak feedforward currents. Another useful function of corticocortical interactions is that they modulate the effects of sparse LGN inputs by filling in potential gaps in the orientation map. No less important is the constant competition between the $\mathrm{E}$ and I populations. The precarious balancing act between these two populations puts the system in a state of high gain, making it very sensitive to small changes in input, as we saw in the analysis of the MR distribution. Furthermore, recurrent excitation coupled with recurrent inhibition helps to produce diversity in neuronal responses enabling cortex to discriminate among a wider range of stimuli (Kang et al., 2004).

Through dynamic interactions among neurons, our network model exhibits behaviors far more complex than can be expected from the LIF equations (Materials and Methods, Equations of neuronal dynamics) that govern the dynamics of individual cells. For a start, there is a great deal of balancing and regulation within the cortical network. When stimulated, E neurons magnify the drive at the same time that I neurons put things in check. Properties (e.g., OS) conferred upon a fraction of the population are shared with the rest of the population, yet the same system that has an averaging effect on its constituent cells (as in the smoothing of the orientation map) also produces great diversities in firing rates, in circular variance, in spatial frequency preferences, and in modulation ratios. The diversity of functional properties is emergent, i.e., it cannot be deduced from the behaviors of single neurons or even a handful of neurons but arises only through the interaction of the many constituent parts of the network.

Emergent behaviors are the hallmark of complex dynamical systems. As our model outputs closely resemble many sets of experimental data, we propose that the visual cortex is, like our model, a complex dynamical system. As such, it is driven largely by population activity, and to understand it requires that we study not only individual neurons but also population dynamics, in particular dynamic interactions among neurons connected by local and medium range circuitries.

\section{Orientation-specific dynamic responses}

Our model generates partially synchronized firing in the gamma band $(30-90 \mathrm{~Hz})$ when driven by drifting gratings (Fig. 9A-C). The response is stimulus dependent and orientation specific: there is very little synchronized firing in the background, but strong synchrony was evident at high contrast in domains preferring an orientation aligned with the grating. Synchronized spiking is more effective in producing recurrent excitation locally, and indirect inhibition in a slightly larger area through the widespread excitation of I neurons by E neurons (Fig. 1D). Therefore, gamma-band synchronization at the preferred orientation is a very effective way for the cortical network to enhance OS.

As mentioned in Results, others have conjectured that gamma-band rhythms contribute to OS, based on cortical data (Volgushev et al., 2002; Womelsdorf et al., 2012) and on an abstract model (de Almeida et al., 2009). Now we have shown in our realistic, data-driven model that gamma-band dynamics are closely linked to OS. This is an entirely emergent property of the model. The dynamical characteristics observed in the model are very similar to data on visually induced gamma-band activity in real V1 (Eckhorn et al., 1988; Gray and Singer, 1989; Volgushev et al., 2002; Kayser and König, 2004). Notice also that the synchronization of the model network is asymmetric; the I cells are much more synchronized to the population than are the E cells (Fig. 9), which is another emergent model property that resembles V1 data (Hasenstaub et al., 2005).

Unlike the earlier PING model (Whittington et al., 2000), our model predicts that, in gamma-band fluctuations, only small fractions of the local population are involved in each firing event, and that individual neurons exhibit quite irregular behaviors despite the quasi-oscillatory activity seen on the population level. These predictions echo those of Rangan and Young (2013) and Chariker and Young (2015).

\section{Comparison with earlier work}

To our knowledge, the model presented here is the first realistic model that has modeled accurately the sparseness of magnocellular LGN inputs to the macaque V1 cortex and also successfully derived OS directly from these inputs. Earlier, more abstract models proposed that recurrent cortical interactions could produce high levels of OS even when the OS of the LGN input was weak (Douglas et al., 1995; Ben-Yishai et al., 1995; Somers et al., 1995; Hansel and Sompolinsky, 1997). Our model supports these ideas but goes beyond them in its realistic depiction of the anatomy, network dynamics, and the linkage between network dynamics and cortical function. 
The present model is very different and much improved compared with earlier large-scale models, such as those of McLaughlin et al. (2000) and Tao et al. (2004, 2006). First, our focus on dynamics and on population activity is novel; this represents a paradigm shift that we believe will have implications for future directions of the field (see below). Second, the present model incorporates much more realistic neuroanatomy. In addition to sparse LGN $\rightarrow$ V1 connectivity, our modeling of the sparse E-E connections and denser I connections is data driven, as is our modeling of the feedback from layer 6; we have used biological guidance in virtually all aspects of our modeling when it is available. Third, our parameter determination process is more systematic, and it has been made transparent (Materials and Methods, Parameter determination). Last but not least, the present model is more comprehensive than all previous ones that we know of. We sought not just to replicate one or two aspects of V1 behavior but to reproduce, in a single model and from a single set of parameters, many V1 phenomena, such as orientation and spatial frequency selectivity, spontaneous and driven firing rates, gamma rhythms, simple versus complex cells, and neuronal diversity in all aspects of the above.

The present model differs also from rate models of V1 function, such as those of Priebe and Ferster (2008), Persi et al. (2011), Rubin et al. (2015), and Goris et al. (2015), in its emphasis on temporal dynamics as opposed to the use of fixed transducer functions as a means to account for cortical transformation of visual inputs into the population distributions of spike-firing rates. We appreciate the mathematical appeal of filters and simplified rate models, but approaches of this type downplay dynamic interactions among cortical neurons. As we have shown, such interactions are an integral part of cortical processing.

\section{Future directions in computational neuroscience}

A comprehensive, large-scale model of the cortex is not without cost. In particular, it cannot be as simple as phenomenological models that focus on one or two sets of behaviors at a time, or on the properties of single neurons. Comprehensive and phenomenological models serve very different purposes: phenomenological models typically seek to suggest analogies or to offer simplified mathematical descriptions. Comprehensive population models, such as the one we have presented here, seek to link cellular properties and network structure to dynamics and function, the ultimate goal being to use these models to test hypotheses and to suggest future experiments. We propose that for areas of the brain about which there are sufficient data, such as the visual cortex, it is time to move to next-generation models that are more comprehensive, data driven, and dynamic. Such a move would constitute a paradigm shift in computational neuroscience, and the present model is a step in that direction.

With regard to other regions of the cerebral cortex, much more anatomical and functional data than are currently available are needed for detailed modeling. However, the linkage between dynamics and function is not limited to V1 cortex. In many cortical areas, cortical activation is associated with increased gamma-band power in the local field potential (motor cortex, Murthy and Fetz, 1996; auditory cortex, Brosch et al., 2002; parietal cortex, Pesaran et al., 2002; prefrontal cortex, GonzalezBurgos and Lewis, 2008), as in V1 (Eckhorn et al., 1988; Gray and Singer, 1989; Volgushev et al., 2002; Henrie and Shapley, 2005; Ray and Maunsell, 2010). We propose that analysis of the connections among anatomy, function, and dynamics in the visual cortex may reveal principles that generalize to the entire cerebral cortex.

\section{References}

Alonso JM, Usrey WM, Reid RC (2001) Rules of connectivity between geniculate cells and simple cells in cat primary visual cortex. J Neurosci 21:4002-4015.

Angelucci A, Sainsbury K (2006) Contribution of feedforward thalamic afferents and corticogeniculate feedback to the spatial summation area of macaque V1 and LGN. J Comp Neurol 498:330-351. CrossRef Medline

Batschelet E (1981) Circular statistics in biology. London: Academic.

Beaulieu C, Kisvarday Z, Somogyi P, Cynader M, Cowey A (1992) Quantitative distribution of GABA-immunopositive and -immunonegative neurons and synapses in the monkey striate cortex (area 17). Cereb Cortex 2:295-309. CrossRef

Beierlein M, Gibson JR, Connors BW (2003) Two dynamically distinct inhibitory networks in layer 4 of the neocortex. J Neurophysiol 90:29873000. CrossRef

Ben-Yishai R, Bar-Or RL, Sompolinsky H (1995) Theory of orientation tuning in visual cortex. Proc Natl Acad Sci U S A 92:3844-3848. CrossRef

Binzegger T, Douglas RJ, Martin KA (2009) Topology and dynamics of the canonical circuit of cat V1. Neural Netw 22:1071-1078. CrossRef Medline

Blasdel GG, Lund JS (1983) Termination of afferent axons in macaque striate cortex. J Neurosci 3:1389-1413.

Borg-Graham LJ, Monier C, Fregnac Y (1998) Visual input evokes transient and strong shunting inhibition in visual cortical neurons. Nature 393: 369-373. CrossRef

Brosch M, Budinger E, Scheich H (2002) Stimulus-related gamma oscillations in primate auditory cortex. J Neurophysiol 87:2715-2725. Medline

Buzsáki G, Mizuseki K (2014) The log-dynamic brain: how skewed distributions affect network operations. Nat Neurosci Rev 15:264-278. CrossRef Medline

Callaway EM (1998) Local circuits in primary visual cortex of the macaque monkey. Annu Rev Neurosci 21:47-74. CrossRef Medline

Cardin JA, Palmer LA, Contreras D (2007) Stimulus feature selectivity in excitatory and inhibitory neurons in primary visual cortex. J Neurosci 27:10333-10344. CrossRef Medline

Chariker L, Young LS (2015) Emergent spike patterns in neuronal populations. J Comput Neurosci 38:203-220. CrossRef Medline

Chatterjee S and Callaway EM (2003) Parallel colour-opponent pathways to primary visual cortex. Nature 426:668-671. CrossRef Medline

Connolly M, Van Essen D (1984) The representation of the visual field in parvicellular and magnocellular layers of the lateral geniculate nucleus in the macaque monkey. J Comp Neurol 226:544-564. CrossRef Medline

de Almeida L, Idiart M, Lisman JE (2009) A second function of gamma frequency oscillations: an E\%-max winner-take-all mechanism selects which cells fire. J Neurosci 29:7497-7503. CrossRef Medline

Defelipe J, González-Albo MC, Del Río MR, Elston GN (1999) Distribution and patterns of connectivity of interneurons containing calbindin, calretinin, and parvalbumin in visual areas of the occipital and temporal lobes of the macaque monkey. J Comp Neurol 412:515-526. CrossRef Medline

De Valois RL, Albrecht DG, Thorell LG (1982) Spatial frequency selectivity of cells in macaque visual cortex. Vision Res 22:545-559. CrossRef Medline

Disney AA, Aoki C, Hawken MJ (2012) Cholinergic suppression of visual responses in primate V1 is mediated by GABAergic inhibition. J Neurophysiol 108:1907-1923. CrossRef Medline

Douglas RJ, Koch C, Mahowald M, Martin KA, Suarez HH (1995) Recurrent excitation in neocortical circuits. Science 269:981-985. CrossRef Medline

Eckhorn R, Bauer R, Jordan W, Brosch M, Kruse W, Munk M, Reitboeck HJ (1988) Coherent oscillations: a mechanism of feature linking in the visual cortex? Multiple electrode and correlation analyses in the cat. Biol Cybern 60:121-130. CrossRef Medline

Fitzpatrick D, Lund JS, Blasdel GG (1985) Intrinsic connections of macaque striate cortex: afferent and efferent connections of lamina 4C. J Neurosci 5:3329-3349. Medline

Gibson JR, Beierlein M, Connors BW (2005) Functional properties of electrical synapses between inhibitory interneurons of neocortical layer 4 . J Neurophysiol 93:467-480. CrossRef Medline

Gil Z, Connors BW, Amitai Y (1999) Efficacy of thalamocortical and intracortical synaptic connections: quanta, innervation, and reliability. Neuron 23:385-397. CrossRef Medline

Gonzalez-Burgos G, Lewis DA (2008) GABA neurons and the mechanisms 
of network oscillations: implications for understanding cortical dysfunction in schizophrenia. Schizophr Bull 34:944-961. CrossRef Medline

Goris RL, Simoncelli EP, Movshon JA (2015) Origin and function of tuning diversity in macaque visual cortex. Neuron 88:819-831. CrossRef Medline

Gray CM, Singer W (1989) Stimulus-specific neuronal oscillations in orientation columns of cat visual cortex. Proc Natl Acad Sci U S A 86:16981702. CrossRef Medline

Hansel D, Sompolinsky H (1997) Modeling feature selectivity in local cortical circuits. In: Methods in neuronal modeling: from synapse to networks, Chap 13, Ed 2 (Koch C, Segev I, eds). Cambridge, MA: MIT.

Hasenstaub A, Shu Y, Haider B, Kraushaar U, Duque A, McCormick DA (2005) Inhibitory postsynaptic potentials carry synchronized frequency information in active cortical networks. Neuron 47:423-435. CrossRef Medline

Hawken MJ, Shapley RM, Grosof DH (1996) Temporal frequency selectivity in monkey visual cortex. Vis Neurosci 13:477-492. CrossRef Medline

Henrie JA, Shapley R (2005) LFP power spectra in V1 cortex: the graded effect of stimulus contrast. J Neurophysiol 94:479-490. CrossRef Medline

Hirsch JA, Martinez LM, Pillai C, Alonso JM, Wang Q, Sommer FT (2003) Functionally distinct inhibitory neurons at the first stage of visual cortical processing. Nat Neurosci 6:1300-1308. CrossRef Medline

Hoffman KP, Stone J (1971) Conduction velocity of afferents to cat visual cortex: a correlation with cortical receptive field properties. Brain Res 32:460-466. CrossRef Medline

Holmgren C, Harkany T, Svennenfors B, Zilberter Y (2003) Pyramidal cell communication within local networks in layer $2 / 3$ of rat neocortex. J Physiol 551:139-153. CrossRef Medline

Hubel DH, Wiesel TN (1962) Receptive fields, binocular interaction and functional architecture in the cat's visual cortex. J Physiol 160:106-154. CrossRef Medline

Isaacson JS, Scanziani M (2011) How inhibition shapes cortical activity. Neuron 72:231-243. CrossRef Medline

Kang K, Shapley RM, Sompolinsky H (2004) Information tuning of populations of neurons in primary visual cortex. J Neurosci 24:3726-3735. CrossRef Medline

Kayser C, König P (2004) Stimulus locking and feature selectivity prevail in complementary frequency ranges of V1 local field potentials. Eur J Neurosci 19:485-489. CrossRef Medline

Koch C (1999) Biophysics of computation. Oxford, UK: Oxford UP.

Lien AD, Scanziani M (2013) Tuned thalamic excitation is amplified by visual cortical circuits. Nat Neurosci 16:1315-1323. CrossRef Medline

Lin IC, Xing D, Shapley R (2012) Integrate-and-fire vs Poisson models of LGN input to V1 cortex: noisier inputs reduce orientation selectivity. J Comput Neurosci 33:559-572. CrossRef Medline

Lisman JE, Coyle JT, Green RW, Javitt DC, Benes FM, Heckers S, Grace AA (2008) Circuit- based framework for understanding neurotransmitter and risk gene interactions in schizophrenia. Trends Neurosci 31:234-242. CrossRef Medline

Liu B, Li YT, Ma WP, Pan CJ, Zhang LI, Tao HW (2011) Broad inhibition sharpens orientation selectivity by expanding input dynamic range in mouse simple cells. Neuron 71:542-554. CrossRef Medline

Livingstone MS, Hubel DH (1984) Anatomy and physiology of a color system in the primate visual cortex. J Neurosci 4:309-356. Medline

Lund JS, Yoshioka T, Levitt JB (1993) Comparison of intrinsic connectivity in different areas of macaque monkey cerebral cortex. Cereb Cortex 3:148-162. CrossRef Medline

Lund JS, Angelucci A, Bressloff PC (2003) Anatomical substrates for functional columns in macaque monkey primary visual cortex. Cereb Cortex 12:15-24. CrossRef Medline

Mardia KV (1972) Statistics of directional data. London: Academic.

Martin KA (1988) The Wellcome Prize lecture. From single cells to simple circuits in the cerebral cortex. Q J Exp Physiol 73:637-702. CrossRef Medline

McLaughlin D, Shapley R, Shelley M, Wielaard DJ (2000) A neuronal network model of sharpening and dynamics of orientation tuning in an input layer of macaque primary visual cortex. Proc Natl Acad Sci U S A 97: 8087-8092. CrossRef Medline

Monier C, Chavane F, Baudot P, Graham LJ, Frégnac Y (2003) Orientation and direction selectivity of synaptic inputs in visual cortical neurons: a diversity of combinations produces spike tuning. Neuron 37:663-680. CrossRef Medline

Murthy VN, Fetz EE (1996) Synchronization of neurons during local field potential oscillations in sensorimotor cortex of awake monkeys. J Neurophysiol 76:3968-3982. Medline

Nowak LG, Sanchez-Vives MV, McCormick DA (2008) Lack of orientation and direction selectivity in a subgroup of fast-spiking inhibitory interneurons: cellular and synaptic mechanisms and comparison with other electrophysiological cell types. Cereb Cortex 18:1058-1078. CrossRef Medline

Obermayer K, Blasdel GG (1993) Geometry of orientation and ocular dominance columns in monkey striate cortex. J Neurosci 13:4114-4129. Medline

Oswald AM, Reyes AD (2008) Maturation of intrinsic and synaptic properties of layer $2 / 3$ pyramidal neurons in mouse auditory cortex. J Neurophysiol 99:2998-3008. CrossRef Medline

Paik SB, Ringach DL (2011) Retinal origin of orientation maps in visual cortex. Nat Neurosci 14:919-925. CrossRef Medline

Persi E, Hansel D, Nowak L, Barone P, van Vreeswijk C (2011) Power-law input-output transfer functions explain the contrast-response and tuning properties of neurons in visual cortex. PLoS Comput Biol 7:e1001078. CrossRef Medline

Pesaran B, Pezaris JS, Sahani M, Mitra PP, Andersen RA (2002) Temporal structure in neuronal activity during working memory in macaque parietal cortex. Nat Neurosci 5:805-811. CrossRef Medline

Priebe NJ, Ferster D (2008) Inhibition, spike threshold, and stimulus selectivity in primary visual cortex. Neuron 57:482-497. CrossRef Medline

Rangan AV, Young LS (2013) Emergent dynamics in a model of visual cortex. J Comput Neurosci 35:155-167. CrossRef Medline

Ray S, Maunsell JH (2010) Differences in gamma frequencies across visual cortex restrict their possible use in computation. Neuron 67:885-896. CrossRef Medline

Reich DS, Victor JD, Knight BW, Ozaki T, Kaplan E (1997) Response variability and timing precision of neuronal spike trains in vivo. J Neurophysiol 77:2836-2841. Medline

Ringach DL (2007) On the origin of the functional architecture of the cortex. PLoS One 2:e251. CrossRef Medline

Ringach DL, Shapley RM, Hawken MJ (2002) Orientation selectivity in macaque V1: diversity and laminar dependence. J Neurosci 22:5639-5651. Medline

Roxin A, Brunel N, Hansel D, Mongillo G, van Vreeswijk C (2011) On the distribution of firing rates in networks of cortical neurons. J Neurosci 31:16217-16226. CrossRef Medline

Rubin DB, Van Hooser SD, Miller KD (2015) The stabilized supralinear network: a unifying circuit motif underlying multi-input integration in sensory cortex. Neuron 85:402-417. CrossRef Medline

Schoonover CE, Tapia JC, Schilling VC, Wimmer V, Blazeski R, Zhang W, Mason CA, Bruno RM (2014) Comparative strength and dendritic organization of thalamocortical and corticocortical synapses onto excitatory layer 4 neurons. J Neurosci 34:6746-6758. CrossRef Medline

Silveira LC, Perry VH (1991) The topography of magnocellular projecting ganglion cells (M-ganglion cells) in the primate retina. Neuroscience 40: 217-237. CrossRef Medline

Sincich LC, Horton JC (2005) The circuitry of V1 and V2: integration of color, form, and motion. Annu Rev Neurosci 28:303-326. CrossRef Medline

Skottun BC, De Valois RL, Grosof DH, Movshon JA, Albrecht DG, Bonds AB (1991) Classifying simple and complex cells on the basis of response modulation. Vis Res 31:1079-1086. Medline

Soma S, Shimegi S, Osaki H, Sato H (2012) Cholinergic modulation of response gain in the primary visual cortex of the macaque. J Neurophysiol 107:283-291. CrossRef Medline

Somers DC Nelson SB, Sur M (1995) An emergent model of orientation selectivity in cat visual cortical simple cells. J Neurosci 15:5448-5465. Medline

Stratford KJ, Tarczy-Hornoch K, Martin KA, Bannister NJ, Jack JJ (1996) Excitatory synaptic inputs to spiny stellate cells in cat visual cortex. Nature 382:258-261. CrossRef Medline

Swadlow HA (1988) Efferent neurons and suspected interneurons in binocular visual cortex of the awake rabbit: receptive fields and binocular properties. J Neurophysiol 59:1162-1187. Medline 
Tanaka K (1983) Cross-correlation analysis of geniculostriate neuronal relationships in cats. J Neurophysiol 49:1303-1318. Medline

Tao L, Shelley M, McLaughlin D, Shapley R (2004) An egalitarian network model for the emergence of simple and complex cells in visual cortex. Proc Natl Acad Sci U S A 101:366-371. CrossRef Medline

Tao L, Cai D, McLaughlin DW, Shelley MJ, Shapley R (2006) Orientation selectivity in visual cortex by fluctuation-controlled criticality. Proc Natl Acad Sci U S A 103:12911-12916. CrossRef Medline

van Vreeswijk C, Sompolinsky H (1996) Chaos in neuronal networks with balanced excitatory and inhibitory activity. Science 274:1724-1726. CrossRef Medline

Volgushev M, Pernberg J, Eysel UT (2002) A novel mechanism of response selectivity of neurons in cat visual cortex. J Physiol 540:307-320. CrossRef Medline

Whittington MA, Traub RD, Kopell N, Ermentrout B, Buhl EH (2000) Inhibition-based rhythms: experimental and mathematical observations on network dynamics. Int J Psychophysiol 38:315-336. CrossRef Medline

Wielaard DJ, Shelley M, McLaughlin D, Shapley R(2001) How simple cells are made in a nonlinear network model of the visual cortex. J Neurosci 21:5203-5211.

Wiser AK, Callaway EM (1996) Contributions of individual layer 6 pyramidal neurons to local circuitry in macaque primary visual cortex. J Neurosci 16:2724-2739. Medline
Womelsdorf T, Lima B, Vinck M, Oostenveld R, Singer W, Neuenschwander S, Fries P (2012) Orientation selectivity and noise correlation in awake monkey area V1 are modulated by the gamma cycle. Proc Natl Acad Sci U S A 109:4302-4307. CrossRef Medline

Xing D, Yeh CI, Shapley RM (2009) Spatial spread of the local field potential and its laminar variation in visual cortex. J Neurosci 29:11540-11549. CrossRef Medline

Xing D, Ringach DL, Hawken MJ, Shapley RM (2011) Untuned suppression makes a major contribution to the enhancement of orientation selectivity in macaque v1. J Neurosci 31:15972-15982. CrossRef Medline

Xing D, Yeh CI, Burns S, Shapley RM (2012) Laminar analysis of visually evoked activity in the primary visual cortex. Proc Natl Acad Sci U S A 109:13871-13876. CrossRef Medline

Yeh CI, Xing D, Williams PE, Shapley RM (2009) Stimulus ensemble and cortical layer determine V1 spatial receptive fields. Proc Natl Acad Sci U S A 106:14652-14657. CrossRef Medline

Yoshioka T, Levitt JB, Lund JS (1994) Independence and merger of thalamocortical channels within macaque monkey primary visual cortex: anatomy of interlaminar projections. Vis Neurosci 11:467-489. CrossRef Medline

Zhu W, Xing D, Shelley M, Shapley R (2010) Correlation between spatial frequency and orientation selectivity in V1 cortex: implications of a network model. Vision Res 50:2261-2273. CrossRef Medline 